\title{
Resource Oriented Decision Making for Treatment of Metastatic Colorectal Cancer ( $m C R C)$ in a Lower-Middle Income Country: Egyptian Foundation of Medical Sciences (EFMS) Consensus Recommendations 2020
}

\author{
Noha Rashad (D)', Mohamed Abdulla ${ }^{2}$, Mohamed Farouk ${ }^{3}$, Yasser Elkerm ${ }^{4}$, Salem Eid Salem (D) ${ }^{5}$, Maha Yahia ${ }^{5}$, \\ Amr S Saad ${ }^{6}$, Ahmed Hassan Abdel Aziz ${ }^{6}$, Ghada Refaat ${ }^{6}$, Ibrahim Awad ${ }^{7}$, Maha EINaggar ${ }^{8}$, Khaled Kamal ${ }^{6}$, \\ Basel Refky ${ }^{9}$, Mohamed Abdelkhalek $\mathbb{D}^{9}$, Ahmed Touny ${ }^{10}$, Loay Kassem $\mathbb{D}^{2}$, Emad Shash $\mathbb{D}^{5}$, Abdelhay A Abdelhay ${ }^{1}$, \\ Bahaa Eldin Mahmoud ' ', Karima Oualla ${ }^{12}$, Nesrine Chraiet ${ }^{13}$, Hussein AwadElkarim H Maki ${ }^{14}$, Yasser Abdel Kader ${ }^{2}$ \\ 'Medical Oncology Department, Faculty of Medicine, Suez University, Suez, Egypt; ${ }^{2}$ Clinical Oncology and Nuclear Medicine Department, Kasr Al-Aini \\ Medical School, Cairo University, Cairo, Egypt; ${ }^{3}$ Department of Clinical Oncology, Faculty of Medicine, Alexandria University, Alexandria, Egypt; \\ ${ }^{4}$ Department of Cancer Management and Research, Medical Research Institute Hospital, University of Alexandria, Alexandria, Egypt; ${ }^{5}$ Department of \\ Medical Oncology, National Cancer Institute ( $\mathrm{NCl}$ ), Cairo University, Cairo, Egypt; ${ }^{6}$ Clinical Oncology and Nuclear Medicine Department, Faculty of \\ Medicine, Ain Shams University, Cairo, Egypt; ${ }^{7}$ Department of Clinical Oncology and Nuclear Medicine, Faculty of Medicine, Mansoura University, \\ Mansoura, Egypt; ${ }^{8}$ Clinical Oncology Department, Assiut University Hospital, Assiut, Egypt; ${ }^{9}$ Department of Surgical Oncology, Oncology Center \\ Mansoura University, Mansoura, Egypt; ${ }^{10}$ Department of Surgical Oncology, National Cancer Institute, Cairo University, Cairo, Egypt; ${ }^{\prime \prime D e p a r t m e n t}$ \\ of Diagnostic Radiology, Cairo University, Giza, Egypt; ${ }^{2}$ Medical Oncology Department, Hassan II University Hospital Sidi Mohamed Ben Abdellah \\ University, Fes, Morocco; ${ }^{13}$ Medical Oncology Department, Salah Azaiez National Cancer Institute, Tunis, Tunisia; ${ }^{14}$ Clinical Oncology Department, \\ Ahfad University for Women, Khartoum, Sudan
}

Correspondence: Noha Rashad, Medical Oncology Department, Faculty of Medicine, Suez University, Faisal, Suez Governorate, Egypt, Tel +20 I225I57339, Email Nohal6880@gmail.com

Purpose: Colorectal cancer (CRC) is the third most commonly diagnosed cancer worldwide and the second cause of cancer related mortality. Treatment options for patients with metastatic CRC (mCRC) expanded during the last two decades, with introduction of new chemotherapeutic and targeted agents. Egypt is a lower middle-income country; Egyptian health care system is fragmented with wide diversity in drug availability and reimbursement policies across different health care providing facilities. We report the results of consensus recommendations for treatment of patients with metastatic colorectal cancer developed by Egyptian Foundation of Medical Sciences (EFMS), aiming to harmonize clinical practice through structured expert consensus-based recommendations consistent with the national status. EFMS recommendations could be utilized in other countries with similar economic status.

Methods: EFMS recommendations were developed using a modified Delphi process, with three rounds of voting till the final recommendations were approved. A non-systematic review of literature was conducted before generating the provisional statements. Content experts were asked to vote on some recommendations in two different resource groups (restricted resources and non-restricted resources). External review board of experts from a low income and lower-middle countries voted on the applicability of EFMS recommendations in their countries.

Results: The current recommendations highlighted the discrepancy in health care between restricted and non-restricted resources with expected survival loss and quality of life deterioration. Access to targeted agents in first line is very limited in governmental institutions, and no access to agents approved for third line in patients who failed oxaliplatin and irinotecan containing regimens for patients treated in restricted resource settings.

Conclusion: Management of mCRC in developing countries is a challenge. The currently available resource-stratified guidelines developed by international cancer societies represent a valuable decision-making tool, adaptation to national status in each country based on healthcare system status is required.

Keywords: colorectal cancer CRC, consensus recommendations, metastatic CRC, management in a lower-middle income country

Received: 24 September 2021 Accepted: 27 January 2022

Published: 28 February 2022 


\section{Introduction}

Colorectal cancer (CRC) is the third most commonly diagnosed cancer worldwide, accounting for $9.2 \%$ of cancer-related deaths. ${ }^{1}$ About $30 \%$ of patients present with metastatic disease at diagnosis, and around $50 \%$ of patients will relapse after potentially curative treatment. ${ }^{2,3}$ Colorectal cancer is the sixth most common cancer in Egypt, ${ }^{4}$ around $40 \%$ of patients diagnosed below 45 years old. ${ }^{5}$

The median overall survival (OS) for mCRC patients significantly improved with the addition of irinotecan or oxaliplatin to fluoropyrimidine (5FU) chemotherapy backbone. ${ }^{6,7}$ Patients currently are treated within a "continuum of care model" with sequential exposure to various agents including epidermal growth factor receptors inhibitors (Anti-EGFR), vascular endothelial growth factor inhibitors (Anti-VEGF), immunotherapy and targeted therapies. An incremental increase in median overall survival (OS) with sequential use of active agents reaching around 30 months compared to 11 months with $5 \mathrm{FU}$ alone. ${ }^{8-10}$

Access to approved treatment options and modalities is variable among different countries and within the same country. ${ }^{11-14}$ International oncology societies developed resource stratified clinical practice guidelines for mCRC, ${ }^{11,15}$ and regional adaptation of international guidelines. ${ }^{16}$ National guidelines for each country adjusted according to its health system and policies were also developed. ${ }^{17,18}$ Even with the guideline recommendations developed for limited resource countries, a gap between guidelines and everyday practice is usually noted. ${ }^{19}$ Practicing physicians in low and lowermiddle income countries usually face clinical questions that require further modification of resource stratified guidelines. ${ }^{14}$

Egypt is a lower middle-income country according to the World Bank ranking. ${ }^{20}$ The Egyptian healthcare system has a very complex structure, with governmental and non-governmental institutions providing healthcare services to cancer patients. A wide diversity in drug availability, reimbursement policies and access to health care facilities ${ }^{21}$ makes decision making difficult, ${ }^{22}$ the majority of institutions do not completely fit in the definitions of basic or limited resources provided by international guidelines.

Herein, the results of consensus recommendations for the treatment of patients with metastatic colorectal cancer developed by the Egyptian foundation of medical sciences (EFMS) are reported. The main objective is to offer resourceoriented guidance for physicians working in Egypt treating patients with mCRC. Aiming to improve quality of care and unification of clinical decisions through structured expert consensus-based recommendations tailored according to the national status, reduce variability in cancer care, clarify evidence gaps and identify research needs. We explored the possibility of dissemination and the applicability of EFMS recommendations in countries within the same income group as Egypt (Tunisia ${ }^{23}$ and Morocco $^{24}$ ) as well as in a low income country (Sudan). ${ }^{25}$

\section{Materials and Methods}

EFMS task force was formed in June 2019. A literature review was conducted between June 2019 and September 2019, Clinical practice guidelines published by scientific societies as well as practice-changing clinical trials reports were retrieved. Survey (1) questions and statements were generated covering four main sectors of recommendation: general principles guiding management of $\mathrm{mCRC}$, local interventions in patients with metastatic disease including surgery, Initial Systemic chemotherapy for metastatic colorectal cancer, second-line treatment, and beyond. The task force selected the content expert panel members based on their publications or their leadership of GIT malignancies specialized units. The expert panel included $12 \mathrm{medical} / \mathrm{clinical}$ oncologists, 3 oncology surgeons, and 3 radio-diagnosis and interventional radiology experts. The panel represents various institutions and clinical practice settings, including university hospitals, specialized cancer centers and governmental health insurance facilities in different geographical areas.

On 20th September 2019, an in-person launching meeting with the content expert panel members was held. During the meeting, the panels endorsed the scope of the recommendations, approved the voting formats and questions, agreed on the deadlines, and launched the process.

A modified Delphi consensus development process was used to collect expert opinions. ${ }^{26}$ In Survey (1), expert panel members were asked to give their feedback, comments, and references supporting their point of view on each proposed 
statement. Feedback was collected via email in January 2020. EFMS task force used the feedback on the survey (1) to formulate provisional statement recommendations of survey (2).

Survey (2) was circulated to the content expert members in April 2020 via email. The expert panel members were asked to give their feedback on a Likert scale from 1 to 5 based on their level of agreement with the recommendation as well as the clarity of recommendation ( $1=$ Strongly disagree, $2=$ Disagree, $3=$ neither agree nor disagree, $4=$ Agree and $5=$ strongly agree). Experts were asked to re-write unclear recommendations and give a reference supporting the feedback in case of disagreement or agreement with reservation. Survey (2) results were collected in August 2020. New data emerged in the duration between Survey (1) and the final voting, experts were asked to give their opinion including new data to the consensus recommendations and put it into the final voting process.

EFMS task force collected survey (2) results and analyzed the feedback. The recommendation was considered a reached consensus if the mean level of agreement was $\geq 4.5$, near consensus 3-4.4, the recommendation was considered rejected if the mean level of agreement was $\leq 2.9$. During all surveys, experts were asked to vote on some recommendations in two different resource-oriented settings (restricted resources and non-restricted resources) as defined in the Table 1.

The final voting round was done by a virtual conference held on the 25th of December 2020, including 46 recommendations that did not reach consensus in the survey (2), recommendations required rephrasing with major modification or based on newly released data during 2020. During this meeting, experts discussed the final form of recommendations and voted on the same Likert chart used in the survey (2) to re-evaluate the recommendations and give their opinion.

The task force used ADAPTE methodology to classify recommendation statements into 3 main types according to concordance with existing guidelines. ${ }^{22}$ The final recommendations were developed with the level of agreement and type specified for each recommendation as well as the resource group where the recommendation could be adopted and applied (Tables 2-5). Definitions of levels of agreement and recommendation type are shown in Table 1.

Table I Resources Oriented Groups Definitions, Levels of Agreement and Types of Recommendations

\begin{tabular}{|c|c|}
\hline \multicolumn{2}{|c|}{ Resource Oriented Groups of Recommendations } \\
\hline General & $\begin{array}{l}\text { Recommendations covering areas of management that should be applied and adopted in any practice setting (in restricted } \\
\text { and non-restricted resources). }\end{array}$ \\
\hline $\begin{array}{l}\text { Restricted } \\
\text { resources }\end{array}$ & $\begin{array}{l}\text { Recommendations representing the minimal level accepted for proper patient management, applied in clinical practice } \\
\text { settings with limited budget with no fund or access to targeted therapy. }\end{array}$ \\
\hline $\begin{array}{l}\text { Non-restricted } \\
\text { resources }\end{array}$ & $\begin{array}{l}\text { Recommendations for patient management supported by acceptable evidence with no economic considerations, applied } \\
\text { in private sector, high insurance coverage or clinical practice settings with unlimited re-imbursement policies. Access to } \\
\text { most or all treatment options. }\end{array}$ \\
\hline \multicolumn{2}{|c|}{ Levels of agreement } \\
\hline I & The mean level of agreement $\geq 4.5$ among content expert panel participants. (Strongly recommended). \\
\hline II & The mean level of agreement is between 4.4 and 3.5 among content expert panel participants (Generally recommended). \\
\hline III & $\begin{array}{l}\text { The mean level of agreement is between } 3 \text { and } 3.4 \text { among content expert panel participants OR mean level of agreement } \\
\geq 3.5 \text { with reservations (recommended in specific situations). }\end{array}$ \\
\hline \multicolumn{2}{|c|}{ Type of recommendation } \\
\hline A & $\begin{array}{l}\text { Adopt recommendations from existing guidelines without modification (ASCO, ESMO and NCCN guidelines for } \\
\text { treatment of cancer by site). }\end{array}$ \\
\hline B & $\begin{array}{l}\text { Modified recommendations from existing guidelines or adopted from resource stratified guidelines (ASCO resource } \\
\text { stratified guidelines, NCCN framework for core, basic and enhanced resources). }\end{array}$ \\
\hline C & $\begin{array}{l}\text { Consensus based recommendations based on expert opinion OR earlier publications OR study design other than RCTs / } \\
\text { systematic reviews OR studies recently published and not included yet in the existing guidelines. }\end{array}$ \\
\hline
\end{tabular}


Table 2 Sector I: Consensus Recommendation Statements on General Principles Guiding the Management of mCRC

\begin{tabular}{|c|c|c|c|}
\hline \multicolumn{2}{|r|}{ Recommendation I.I: Factors Guiding Treatment Strategy Planning } & \multirow{2}{*}{$\begin{array}{l}\text { Level of } \\
\text { Agreement } \\
\text { I }\end{array}$} & \multirow{2}{*}{$\begin{array}{l}\text { Type of } \\
\text { Recommendations } \\
\text { A }\end{array}$} \\
\hline I.I.I & $\begin{array}{l}\text { For effective treatment strategy planning, all the following factors should be taken into } \\
\text { consideration (ranked according to importance): patient's fitness for treatment, anatomical } \\
\text { features and extent of disease, biological profile of the tumor, expected treatment toxicity, drug } \\
\text { availability and infrastructure in the treating facility. }\end{array}$ & & \\
\hline 1.1 .2 & $\begin{array}{l}\text { Treatment should be initiated after diagnosis of metastatic disease regardless of severity of } \\
\text { symptoms or disease burden. }\end{array}$ & I & A \\
\hline I.I.3 & $\begin{array}{l}\text { Isolated CEA elevation with no radiological evidence of metastases is not an indication for } \\
\text { treatment. }\end{array}$ & I & A \\
\hline I.I.4 & Patient with rising CEA should be put under close follow up with work-up and radiology. & I & A \\
\hline \multicolumn{2}{|r|}{ Recommendation I.2: Determinants of Patient's Fitness to Treatment } & & \\
\hline 1.2 .1 & $\begin{array}{l}\text { Age could be a factor to be considered in treatment planning, age by itself is not } \\
\text { a contraindication for intensified treatment. }\end{array}$ & I & A \\
\hline 1.2 .2 & $\begin{array}{l}\text { Comprehensive geriatric assessment (CGA) should be done before initiating systemic treatment } \\
\text { in patients } 65 \text { years or older. }\end{array}$ & II & B \\
\hline 1.2 .3 & $\begin{array}{l}\text { The following factors should be fulfilled to consider a patient fit for intensified treatment: } \\
\text { - ECOG PS 0-I. } \\
\text { - No uncontrolled comorbidities. } \\
\text { - Psychologically willing to go for intensified treatment. }\end{array}$ & I & B \\
\hline I.2.4 & $\begin{array}{l}\text { One of the following factors is enough to consider the patient unfit for intensified therapy but } \\
\text { should be treated with less intensified treatment: } \\
\text { - ECOG PS II. } \\
\text { - Major comorbidities (that may affect treatment outcome or enhance treatment related } \\
\text { toxicity or aggravated by cancer treatment). } \\
\text { - Risky social circumstances (living alone, long distance to nearest cancer center) }\end{array}$ & I & B \\
\hline 1.2 .5 & $\begin{array}{l}\text { Any of the following factors is enough to consider the patient unfit for systemic treatment who } \\
\text { should only receive best supportive care (BSC). } \\
\text { - ECOG PS III-IV. } \\
\text { - End organ failure. } \\
\text { - Life threatening comorbidities with life expectancy less than } 6 \text { months. }\end{array}$ & II & B \\
\hline \multicolumn{2}{|r|}{ Recommendations 1.3: Anatomical Features and Extent of Disease } & & \\
\hline I.3.1 & $\begin{array}{l}\text { Right sided tumors are defined as: tumors arising from ascending colon, transverse colon till } \\
\text { splenic flexure. }\end{array}$ & 1 & A \\
\hline 1.3 .2 & $\begin{array}{l}\text { Left sided tumors are defined as: tumors arising from descending colon, sigmoid colon as well as } \\
\text { tumors of rectal primary. }\end{array}$ & I & A \\
\hline 1.3 .3 & $\begin{array}{l}\text { Patients with solitary site metastatic involvement (including liver/lung and peritoneum) should be } \\
\text { referred to a facility with MDT for assessment of resectability (if not available in the primary } \\
\text { cancer care institute). }\end{array}$ & I & A \\
\hline 1.3 .4 & $\begin{array}{l}\text { Patients with non-regional/distant lymph node, bone and brain metastases are not candidates for } \\
\text { radical surgical intervention in general, only in selected cases. }\end{array}$ & II & B \\
\hline
\end{tabular}

(Continued) 
Table 2 (Continued).

\begin{tabular}{|c|c|c|c|c|}
\hline 1.3 .5 & \multicolumn{2}{|c|}{$\begin{array}{l}\text { - Oligometastatic disease is defined as: } \\
\text { The existence of metastases at up to } 2 \text { or occasionally } 3 \text { sites and } 5 \text { or sometimes more lesions, } \\
\text { predominantly visceral and occasionally lymphonodal. These are the primary, and other involved } \\
\text { sites such as the liver, lung, peritoneum, nodes and ovary. }\end{array}$} & I & A \\
\hline \multicolumn{3}{|c|}{ Recommendation I.4: Pathological and Molecular Features of the Tumor } & & \\
\hline I.4.1 & \multicolumn{2}{|c|}{$\begin{array}{l}\text { Adenocarcinoma with focal neuroendocrine differentiation, mucinous and signet ring tumors } \\
\text { should be offered standard chemotherapy for adenocarcinoma (NOS). }\end{array}$} & I & A \\
\hline 1.4.2 & \multicolumn{2}{|c|}{$\begin{array}{l}\text { Basic molecular biomarkers panel before defining treatment strategy should include only } \\
\text { predictive biomarkers with known implications in treatment decision (according to treatment } \\
\text { options approved for each line of treatment). }\end{array}$} & I & C \\
\hline 1.4.3 & \multicolumn{2}{|c|}{ Tissues obtained from primary lesion or metastatic lesions could be used biomarker studies. } & I & A \\
\hline I.4.4 & \multicolumn{2}{|c|}{$\begin{array}{l}\text { In absence of national data on the prevalence of DPD and UGTIA I deficiency, it should not be } \\
\text { routinely tested. }\end{array}$} & 1 & C \\
\hline \multicolumn{3}{|c|}{ Recommendation I.5: Defining Treatment Intensity } & & \\
\hline 1.5.1 & \multirow[t]{2}{*}{$\begin{array}{l}\text { Restricted } \\
\text { resources }\end{array}$} & $\begin{array}{l}\text { Intensified treatment: Doublet (FOLFOX, XELOX, and FOLFIRI) or triplet } \\
\text { (FOLFOXIRI) chemotherapy regimen. }\end{array}$ & 1 & B \\
\hline 1.5 .2 & & $\begin{array}{l}\text { Less intensified treatment options: Monotherapy with fluoropyrimidines } \\
\text { (degramont /capecitabine), or a reduced dose doublet (FOLFOX /FOLFIRI) }\end{array}$ & ॥ & B \\
\hline 1.5 .3 & \multirow{2}{*}{$\begin{array}{l}\text { Non- } \\
\text { restricted } \\
\text { resources }\end{array}$} & $\begin{array}{l}\text { Intensified treatment: Doublet (FOLFOX, XELOX, FOLFIRI) or triplet } \\
\text { (FOLFOXIRI) chemotherapy regimen +biological agents (anti-EGFR/anti-VEGF). }\end{array}$ & II & A \\
\hline 1.5 .4 & & $\begin{array}{l}\text { Less intensified treatment: Fluoropyrimidines with biologic agents } \\
\text { (capecitabine/bevacizumab) or FOLFOX + panitumumab followed by } \\
\text { panitumumab maintenance. }\end{array}$ & II & C \\
\hline
\end{tabular}

External review board with 3 experts representing a low-income country (Sudan) and lower-middle income countries (Morocco and Tunisia) were asked to assess the recommendations for applicability in their countries. Experts were asked to vote on the level of agreement with the recommendations using the same Likert scale previously utilized, applicability (applicable, not applicable, applicable in some centers) and the barriers preventing adaptation of the recommendations (budget/infrastructure/access).

The final manuscript was approved by all the panel members, target users review is planned after publication and dissemination of the recommendations. Feedback from stakeholders, decision-makers, and different institution representatives is encouraged to measure the applicability of the consensus-based recommendations in different healthcare facilities.

As per the Egyptian law of biomedical research, application to IRB is not requested as no human or animal subjects were included.

\section{Results}

Summary of the consensus recommendations with the level of agreement and type of recommendations are presented in Tables 2-5. Each sector is dedicated to answer a group of clinical questions covering a well-defined aspect of clinical practice. External review boards voting on applicability of recommendations for restricted resources are summarized in Table 6 . 
Table 3 Sector 2: Consensus Recommendation Statements on Local Interventions in Patients with mCRC and the Role of Systemic Chemotherapy Combined with Surgery

\begin{tabular}{|c|c|c|c|}
\hline \multicolumn{2}{|r|}{ Recommendation 2.1: Factors Guiding Treatment Strategy Planning } & \multirow{2}{*}{$\begin{array}{l}\text { Level of } \\
\text { Agreement } \\
1\end{array}$} & \multirow{2}{*}{$\begin{array}{l}\text { Type of } \\
\text { Recommendations } \\
\text { B }\end{array}$} \\
\hline 2.1.1 & $\begin{array}{l}\text { For Patients with Oligometastatic disease, local ablative or locoregional measures in addition to } \\
\text { systemic treatment may improve treatment outcome and should be considered (taking in } \\
\text { account the other biological and anatomical factors). }\end{array}$ & & \\
\hline 2.1.2 & $\begin{array}{l}\text { Patients with Oligometastatic disease with single site involvement (liver, lung and localized } \\
\text { peritoneal disease) should be assessed by MDT including surgeons experienced in } \\
\text { metastatectomy (organ specific surgery) to determine if the patient is resectable/potentially } \\
\text { resectable before initiating systemic treatment. }\end{array}$ & I & A \\
\hline 2.1.3 & $\begin{array}{l}\text { Patients with multiple organ site affection or extensive single site metastases that are not } \\
\text { candidates for surgery/local ablative interventions and should start systemic treatment. }\end{array}$ & I & A \\
\hline 2.1.4 & $\begin{array}{l}\text { If referral to a facility with MDT experienced in metastatectomy is not possible, attempt of } \\
\text { resection should not be done and the patient should start systemic treatment till MDT referral } \\
\text { become possible. }\end{array}$ & 1 & C \\
\hline \multicolumn{2}{|r|}{$\begin{array}{l}\text { Recommendation 2.2: Factors Guiding Decision and Sequence of Treatment in Patients with } \\
\text { Resectable Metastatic Colon Cancer }\end{array}$} & & \\
\hline 2.2.1 & $\begin{array}{l}\text { Surgery should be the upfront treatment modality in patients with resectable metastases fulfilling } \\
\text { the following criteria: } \\
\text { - Meta-chronous metastatic disease. } \\
\text { - Disease free survival more than one year after radical treatment and adjuvant therapy. }\end{array}$ & II & B \\
\hline 2.2 .2 & $\begin{array}{l}\text { Surgery should not be the upfront treatment offered to patients with resectable metastases with } \\
\text { short DFS (less than } 6 \text { month) after adjuvant treatment. }\end{array}$ & $\|$ & C \\
\hline 2.2 .3 & $\begin{array}{l}\text { Chemotherapy as a peri-operative treatment is preferred in patients with uncertain oncological } \\
\text { outcome defined as patients with any of the following criteria: } \\
\text { - Synchronous metastases at time of diagnosis. } \\
\text { - BRAF mutation. }\end{array}$ & III & B \\
\hline \multicolumn{2}{|r|}{ Recommendation 2.3: Organ Specific Criteria for Surgical Resection } & & \\
\hline 2.3.1 & $\begin{array}{l}\text { Isolated liver metastases are considered resectable if they fulfilled the following criteria: } \\
\text { - Less than four in number. } \\
\text { - Largest is less than } 5 \mathrm{~cm} \text { in greatest dimension. } \\
\text { - No extrahepatic disease. } \\
\text { - Adequate remnant liver parenchyma. } \\
\text { - Absence of IVC and hepatic veins confluence invasion. }\end{array}$ & 1 & A \\
\hline 2.3 .2 & $\begin{array}{l}\text { Isolated liver metastases are considered potentially resectable if they fulfilled the following } \\
\text { criteria: } \\
\text { - Presence of multiple or bilobar Mets with highly qualified center both radiologically and } \\
\text { surgically to be able to anticipate the future liver reserve. }\end{array}$ & 1 & B \\
\hline 2.3 .3 & $\begin{array}{l}\text { Isolated lung metastases are considered resectable if they fulfilled the following criteria: } \\
\text { - The ability to achieve a complete extirpation of intrathoracic disease without sacrificing } \\
\text { excessive amounts of normal lung parenchyma. } \\
\text { - Ensuring good cardiopulmonary fitness by testing pulmonary function and exercise tolerance. }\end{array}$ & II & B \\
\hline 2.3.4 & $\begin{array}{l}\text { Isolated lung metastases are considered potentially resectable if they fulfilled the following } \\
\text { criteria: } \\
\text { Same as in liver metastases, with highly qualified centers to ensure future pulmonary reserve. }\end{array}$ & II & B \\
\hline
\end{tabular}

(Continued) 
Table 3 (Continued).

\begin{tabular}{|c|c|c|c|}
\hline 2.3 .5 & $\begin{array}{l}\text { Isolated peritoneal metastases are considered resectable if they fulfilled the following criteria: } \\
\text { - Low PCI (Less than 6) } \\
\text { - Completeness of cytoreduction (CC0) is potentially achievable) } \\
\text { - PS 0-I }\end{array}$ & I & A \\
\hline 2.3 .6 & $\begin{array}{l}\text { Isolated peritoneal metastases are considered potentially resectable if they fulfilled the following } \\
\text { criteria: } \\
\text { - PCI (Less than 6-10) } \\
\text { - PS 0-I }\end{array}$ & I & A \\
\hline 2.3 .7 & $\begin{array}{l}\text { Based on updated results of PRODIGE } 7 \text { trial, HIPEC + cytoreduction surgery is not superior to } \\
\text { cytoreduction alone and should not be performed. }\end{array}$ & II & B \\
\hline 2.3 .8 & $\begin{array}{l}\text { Patients with extrahepatic disease could be submitted to hepatic metastatectomy in very } \\
\text { selected cases. }\end{array}$ & II & C \\
\hline 2.3 .9 & $\begin{array}{l}\text { Patients with oligometastatic disease with multiple site involvement should be treated primarily } \\
\text { with chemotherapy. }\end{array}$ & I & B \\
\hline 2.3.10 & $\begin{array}{l}\text { There is no sufficient evidence on the proper time of surgical resection of primary tumor (on } \\
\text { elective bases) }\end{array}$ & ॥ & C \\
\hline \multicolumn{4}{|c|}{ Recommendation 2.4: Local Ablative Measures } \\
\hline 2.4.1 & $\begin{array}{l}\text { Local ablative measures could be offered in addition to systemic treatment in patients with } \\
\text { Oligometastatic disease and in patients achieving good response to chemotherapy. }\end{array}$ & I & A \\
\hline 2.4 .2 & SPRT plus chemotherapy (FOLFIRI) is an option in selected patients. & III & $\mathrm{C}$ \\
\hline \multicolumn{4}{|c|}{ Recommendation 2.5. Systemic Treatment in Patients with Resectable Metastatic Patients } \\
\hline 2.5.1 & $\begin{array}{l}\text { The benefit of Perioperative chemotherapy is controversial in patients with good prognostic } \\
\text { criteria; surgery should be the upfront treatment modality. }\end{array}$ & II & B \\
\hline 2.5 .2 & $\begin{array}{l}\text { Adjuvant chemotherapy after R0 metastatectomy could be considered in patients with uncertain } \\
\text { oncological outcome/poor oncological outcome, but not recommended in patients with good } \\
\text { prognostic oncological criteria. }\end{array}$ & 1 & B \\
\hline 2.5 .3 & $\begin{array}{l}\text { Perioperative chemotherapy is the preferred option in patients with uncertain prognostic } \\
\text { criteria. FOLFOX or CAPOX for a total duration of } 6 \text { months are acceptable options as } \\
\text { a perioperative treatment. }\end{array}$ & I & A \\
\hline 2.5 .4 & $\begin{array}{l}\text { Adjuvant chemotherapy of choice (after R0 metastatectomy) is FOLFOX/XELOX for } 6 \text { months } \\
\text { duration. }\end{array}$ & I & B \\
\hline 2.5 .5 & $\begin{array}{l}\text { Even in non-restricted resources setting, the addition of Anti-EGFR or anti-VGFR to } \\
\text { perioperative /adjuvant chemotherapy (after R0 metastatectomy) not recommended. }\end{array}$ & 1 & B \\
\hline 2.5 .6 & $\begin{array}{l}\text { The recommendation of perioperative systemic chemotherapy applies to patients with liver/lung/ } \\
\text { peritoneal metastases. }\end{array}$ & ॥ & C \\
\hline \multicolumn{4}{|c|}{$\begin{array}{l}\text { Recommendation 2.6: Systemic Chemotherapy for Potentially Resectable Metastatic } \\
\text { Disease (Conversion Treatment) }\end{array}$} \\
\hline 2.6.1 & $\begin{array}{l}\text { Choice of systemic conversion therapy is guided by tumor molecular profile. } \\
\text { Patients could be classified into three main groups: } \\
\text { I) LT sided, RT sided, wild RAS/BRAF. } \\
\text { 2) RAS mutant tumors. } \\
\text { 3) BRAF mutants. }\end{array}$ & 1 & A \\
\hline
\end{tabular}


Table 3 (Continued).

\begin{tabular}{|c|c|c|c|c|}
\hline 2.6 .2 & \multicolumn{2}{|c|}{ The most effective doublet/triplet chemotherapy should be used. } & I & A \\
\hline 2.6 .3 & \multicolumn{2}{|c|}{ FOLFOX/FOLFIRI are both valid options as conversion chemotherapy. } & I & A \\
\hline 2.6.4 & \multicolumn{2}{|c|}{ XELOX is not an acceptable backbone option to anti-EGFR based treatment. } & I & A \\
\hline 2.6 .5 & \multicolumn{2}{|c|}{ Interval assessment for resectability every 8 weeks should be carried out. } & I & A \\
\hline 2.6.6 & \multicolumn{2}{|c|}{ After RO resection, Anti-EGFR/Anti-VEGF should not be continued. } & $\|$ & A \\
\hline 2.6 .7 & \multicolumn{2}{|c|}{ Total duration of chemotherapy should not exceed 6 months. } & II & A \\
\hline 2.6 .8 & $\begin{array}{l}\text { Restricted } \\
\text { resources }\end{array}$ & $\begin{array}{l}\text { In RAS/BRAF wild patients, Even in restricted budget setting, anti-EGFR should } \\
\text { be added to doublets to improve chances of curable resection regardless of } \\
\text { sidedness. }\end{array}$ & I & A \\
\hline 2.6 .9 & $\begin{array}{l}\text { Restricted } \\
\text { resources }\end{array}$ & $\begin{array}{l}\text { If access to anti-EGFR is not possible, FOLFOXIRI is an acceptable treatment } \\
\text { option. }\end{array}$ & I & C \\
\hline 2.6 .10 & $\begin{array}{l}\text { Non- } \\
\text { restricted } \\
\text { resources }\end{array}$ & $\begin{array}{l}\text { FOLFOXIRI triplet with anti-EGFR is a promising option but not a standard of } \\
\text { care. }\end{array}$ & II & C \\
\hline 2.6 .11 & $\begin{array}{l}\text { Non- } \\
\text { restricted } \\
\text { resources }\end{array}$ & $\begin{array}{l}\text { For RT sided tumors: Anti-VEGF plus XELOX is an acceptable option as } \\
\text { a conversion therapy, although not favorable. }\end{array}$ & III & B \\
\hline 2.6 .12 & $\begin{array}{l}\text { Non- } \\
\text { restricted } \\
\text { resources }\end{array}$ & $\begin{array}{l}\text { In BRAF mutant tumors: Anti-VEGF plus FOLFOXIRI is an acceptable treatment } \\
\text { option as a conversion therapy in selected patients based on PS and } \\
\text { comorbidities index. }\end{array}$ & II & C \\
\hline
\end{tabular}

\section{Recommendations and Discussion}

\section{Sector (I): General Principles Guiding the Management of mCRC}

This sector is dedicated to answer questions regarding the pivotal factors guiding treatment strategy planning and how to choose the proper treatment intensity for each patient. The first pivotal step in treatment strategy planning is evaluating patient fitness to treatment, by assessment of performance status using ECOG (Eastern cooperative oncology group) scale $^{27}$ and the overall health condition. No specific is age considered as an absolute contraindication for intensified chemotherapy. However, for patients above 65 (the median age of patients in most RCTs, range between 60-65), the panel recommends adopting the ASCO recommendation in using the CGA (comprehensive geriatric assessment) score for geriatric patients assessment. ${ }^{28,29}$ CGA score is a decision aiding tool used to evaluate multiple aspects of general health status in the elder population receiving chemotherapy, including comorbidities, risk of fall, and cognitive functions.

Based on the ECOG PS scale and CGA score, patients should be classified into three main categories: fit for intensified treatment, fit for less intensified treatment, and patients not fit for any active treatment that requires only best supportive care (Recommendations 1.2.3, 1.2.4, and 1.2.5; Table 2). Treatment in patients with chronic renal failure under regular hemodialysis as patients with end-organ failure was discussed, dose adjustment and modified hemodialysis schedules could be used. ${ }^{30}$ The panel prefers decision-making case by case based on expected survival with careful monitoring of adverse events. ${ }^{31}$

The second step in decision-making is classifying patients according to tumor characteristics (tumor burden, primary tumor anatomical site, and molecular profile). Patients with Oligometastatic disease represent a special group with a low disease burden and potentially good prognosis. The panel acknowledges the complexity of decisions in patients with Oligometastatic disease due to heterogeneity of this group of patients as well as vague definition. ${ }^{32}$ We choose to adopt the ESMO definition of Oligometastatic disease ${ }^{33}$ (Recommendation 1.3.5). 
Table 4 Sector 3: Initial (First Line) Systemic Chemotherapy for Metastatic Colorectal Cancer, Resection is Not a Goal

\begin{tabular}{|c|c|c|c|c|}
\hline \multicolumn{3}{|c|}{ Recommendation 3.I. Factors affecting decision making in initial treatment. } & \multirow[b]{2}{*}{ II } & \multirow[b]{2}{*}{ A } \\
\hline 3.1 .1 & & $\begin{array}{l}\text { Intensity of treatment should be defined according to fitness, symptomatology and the goal of treatment as } \\
\text { stated in sector (I). }\end{array}$ & & \\
\hline 3.1 .2 & & $\begin{array}{l}\text { In case of a rapidly progressive symptomatic disease, the primary goal of treatment should be maximal } \\
\text { tumor shrinkage. }\end{array}$ & II & A \\
\hline 3.1 .3 & & $\begin{array}{l}\text { In case of asymptomatic disease, the goal of treatment should be disease control with acceptable toxicity } \\
\text { profile. }\end{array}$ & I & A \\
\hline 3.1 .4 & & $\begin{array}{l}\text { The most effective systemic combination chemotherapy should be used primarily regardless of symptoms } \\
\text { or tumor burden. }\end{array}$ & I & A \\
\hline 3.1 .5 & & $\begin{array}{l}\text { All the following factors shall be considered before decision making (Ranked): } \\
\text { I. Fitness (PS and comorbidities as previously approved in section I). } \\
\text { 2. Goal of treatment (tumor shrinkage or disease control). } \\
\text { 3. Sidedness. } \\
\text { 4. Basic molecular profile (as previously stated in section I). } \\
\text { 5. Patient choice and motivation. } \\
\text { 6. Expected toxicity. }\end{array}$ & I & C \\
\hline 3.1 .6 & restricted & $\begin{array}{l}\text { The optimal basic molecular markers panel before treatment strategy planning MUST include: Extended } \\
\text { RAS and BRAF V600. }\end{array}$ & II & B \\
\hline 3.1.7 & Non-restricted. & $\begin{array}{l}\text { The optimal basic molecular markers panel before treatment strategy planning MUST include: Extended } \\
\text { RAS, BRAF V600 and MSI status. }\end{array}$ & II & B \\
\hline 3.1 .8 & Non-restricted. & Her2 testing is not recommended as a predictive marker for EGFR resistance. & II & B \\
\hline 3.1 .9 & General & Tissues obtained from primary lesion or metastatic lesions could be used for molecular testing. & I & A \\
\hline 3.1 .10 & General & $\begin{array}{l}\text { Radiological assessment of response to treatment: Contrast enhanced CT, MRI with diffusion images and } \\
\text { CEA if initially elevated every } 8 \text { to } 12 \text { weeks. }\end{array}$ & I & A \\
\hline 3.1 .11 & General & $\begin{array}{l}\text { Increase in the metabolic activity with no evident radiological progression in PET/CT should not modify } \\
\text { treatment decision. }\end{array}$ & I & B \\
\hline \multicolumn{3}{|c|}{ Recommendation 3.2.systemic treatment in Fit patients, willing to receive intensified treatment. } & & \\
\hline 3.2.1 & General & $\begin{array}{l}\text { FOLFIRI, FOLFOX, XELOX and FOLFOXIRI are all valid options as first line treatment for metastatic } \\
\text { disease. }\end{array}$ & I & A \\
\hline 3.2 .2 & General & $\begin{array}{l}\text { Capecitabine combination with irinotecan (XELIRI/CAPIRI) is not recommended due to high incidence of } \\
\text { toxicity and higher rates of treatment discontinuation compared to FOLFIRI. }\end{array}$ & III & A \\
\hline 3.2 .3 & General & $\begin{array}{l}\text { In patients who relapsed after oxaliplatin containing adjuvant treatment, rechallenge with oxaliplatin could } \\
\text { be considered after } 12 \text { months of the end of adjuvant chemotherapy. }\end{array}$ & I & A \\
\hline 3.2 .4 & $\begin{array}{l}\text { Restricted } \\
\text { resources. }\end{array}$ & $\begin{array}{l}\text { Oxaliplatin could be withdrawn after } 3 \text { months of treatment in responding patients with low disease } \\
\text { burden, reintroduced upon progression. }\end{array}$ & $\|$ & B \\
\hline 3.2 .5 & $\begin{array}{l}\text { Restricted } \\
\text { resources. }\end{array}$ & $\begin{array}{l}\text { In selected cases with PS I and no comorbidities, FOLFOXIRI is an acceptable option if access to biological } \\
\text { agents is not possible. }\end{array}$ & III & B \\
\hline 3.2 .6 & $\begin{array}{l}\text { Restricted } \\
\text { resources. }\end{array}$ & $\begin{array}{l}\text { For most patients, maintenance therapy is preferred over a complete break especially in patients with large } \\
\text { disease volume, good PS and no major adverse events. }\end{array}$ & & \\
\hline 3.2.7 & $\begin{array}{l}\text { Restricted } \\
\text { resources. }\end{array}$ & 5FU or capecitabine single agents are acceptable maintenance options. & III & B \\
\hline
\end{tabular}


Table 4 (Continued).

\begin{tabular}{|c|c|c|c|c|}
\hline 3.2 .8 & $\begin{array}{l}\text { Non-restricted } \\
\text { resources. }\end{array}$ & Anti-EGFR use should be limited to patients with left sided (RAS/BRAF wild) tumors. & II & A \\
\hline 3.2 .9 & $\begin{array}{l}\text { Non-restricted } \\
\text { resources. }\end{array}$ & In patients with LEFT SIDED primary tumors, chemotherapy doublet +anti-EGFR are the preferred option. & 1 & A \\
\hline 3.2.10 & Non-restricted. & $\begin{array}{l}\text { Anti-EGFR with backbone chemotherapy including capecitabine or bolus 5FU is less effective compared to } \\
\text { infusional 5FU based regimens and thus, not preferred. }\end{array}$ & II & A \\
\hline 3.2.11 & Non restricted. & No special preference of one anti-EGFR over the other (cetuximab/panitumumab). & 1 & A \\
\hline 3.2.12 & Non-restricted & $\begin{array}{l}\text { In patients with RIGHT SIDED primary tumors and RAS mutated, chemotherapy doublet +anti-VEGF are } \\
\text { the preferred option. }\end{array}$ & I & A \\
\hline 3.2.13 & Non-restricted. & $\begin{array}{l}\text { In BRAF mutant patients, FOLFOXIRI +bevacizumab is the preferred option in selected fit patients, } \\
\text { doublet chemotherapy with bevacizumab is acceptable option. }\end{array}$ & II & A \\
\hline 3.2.14 & Non-restricted. & Maintenance treatment should be a shared decision with the patient. & 1 & B \\
\hline 3.2.15 & Non-restricted. & $\begin{array}{l}\text { Cap/bev is the maintenance treatment of choice in patients who received CAPOX-bev as first line } \\
\text { treatment. }\end{array}$ & 1 & A \\
\hline 3.2.16 & Non-restricted. & Pembrolizumab single agent is an acceptable option in patients with MSI-H tumors. & II & C \\
\hline \multicolumn{5}{|c|}{ Recommendation 3.3: systemic treatment in patients unfit for intensified treatment, fit for less intensified treatment. } \\
\hline 3.3.1 & Restricted. & $\begin{array}{l}\text { Capecitabine single agent /reduced dose FOLFOX / reduced dose FOLFIRI are acceptable options as } \\
\text { mentioned in sector I. }\end{array}$ & 1 & B \\
\hline 3.3 .2 & Restricted. & $\begin{array}{l}\text { Co-morbidities and ECOG PS are the main factor favoring capectibaine single agent over compination } \\
\text { treatment. }\end{array}$ & 1 & C \\
\hline 3.3 .3 & Restricted. & $\begin{array}{l}\text { For patients receiving capecitabine as a single agent, treatment should continue till disease progression or } \\
\text { unacceptable toxicity. }\end{array}$ & 1 & A \\
\hline 3.3.4 & Non-restricted. & Cap/beva is the treatment of choice regardless of tumor side or tumor molecular profile. & 1 & A \\
\hline 3.3.5 & Non-restricted. & Panitumumab/5FU is also an acceptable option in patients RAS/BRAF wild left sided tumors. & II & C \\
\hline
\end{tabular}

Patients with solitary site metastases or Oligometastatic disease must be evaluated by MDT to classify mCRC patients according to resectability into resectable, potentially resectable or resection is not a goal.

The primary tumor site serves as a surrogate for the molecular profile of the tumor. ${ }^{34}$ The panel agreed to adopt the definition of RT colon as the cecum, ascending, and transverse colon till splenic flexure.

The choice of the basic molecular markers panel should be guided by the resource group; only markers with known predictive roles should be requested. This recommendation applies to initial treatment and subsequent lines.

The third and final step is defining treatment intensity, the treatment decision should be resource oriented. The panel acknowledges that there is no clear cut-off point for defining acceptable or negligible clinical benefit with no costeffectiveness studies available to guide decision making. The main factors used to differentiate between restricted and non-restricted resources are the availability of targeted agents and reimbursement policies for expensive drugs.

For patients treated in a restricted resources setting, chemotherapy doublets or triplets are considered intensified treatment. While in non-restricted resources, intensified treatment options include doublet or triplet plus targeted agents. In patients eligible for less intensified treatment, the panel chose to add FOLFIRI with reduced $\operatorname{dos}^{35}$ to treatment options in restricted resources setting as well as single-agent capecitabine and modified dose FOLFOX. For the nonrestricted resources, the panel considers adding $5 \mathrm{FU} / \mathrm{LV}$ plus panitumumab followed by panitumumab maintenance in 
Table 5 Sector 4: Systemic Treatment in Second Line and Beyond

\begin{tabular}{|c|c|c|c|c|}
\hline \multicolumn{3}{|c|}{ Recommendation 4.I. General principles. } & \multirow{2}{*}{$\begin{array}{l}\text { Level of } \\
\text { agreement. } \\
\text { I }\end{array}$} & \multirow{2}{*}{$\begin{array}{l}\text { Type of } \\
\text { recommendation. } \\
\text { A }\end{array}$} \\
\hline 4.1 .1 & General. & $\begin{array}{l}\text { All patients with acceptable PS, adequate organ function with evident radiological progression } \\
\text { should be considered for } 2^{\text {nd }} \text { line treatment. }\end{array}$ & & \\
\hline 4.1 .2 & & $\begin{array}{l}\text { Increase in the metabolic activity with no evident radiological progression in PET/CT should not } \\
\text { modify treatment decision. }\end{array}$ & II & A \\
\hline 4.1 .3 & & $\begin{array}{l}\text { The main goals of treatment in patients receiving second line chemotherapy are to improve quality } \\
\text { of life and prolong survival. }\end{array}$ & 1 & C \\
\hline 4.1 .4 & & $\begin{array}{l}\text { CEA elevation without evident radiological progression is not considered an indication for } \\
\text { treatment. }\end{array}$ & 1 & C \\
\hline 4.1 .5 & & $\begin{array}{l}\text { The treatment choice in patients progressed after or while receiving FOLFOX is FOLFIRI and vice } \\
\text { versa, no preferable sequence. }\end{array}$ & 1 & A \\
\hline 4.1 .6 & & $\begin{array}{l}\text { Re-challenge with oxaliplatin containing regimen could be considered in patients achieving I year of } \\
\text { PFS With no residual peripheral neuropathy. }\end{array}$ & i & B \\
\hline 4.1 .7 & & $\begin{array}{l}\text { Patients not eligible for intensified treatment who progressed on oxaliplatin based } \\
\text { combination (FOLFOX,XELOX) as first line can receive irinotecan single agent as a second line. }\end{array}$ & 1 & B \\
\hline 4.1 .8 & & $\begin{array}{l}\text { Second line treatment options for patients initially treated with FOLFIRINOX are not clear, } 3^{\text {rd }} \text { line } \\
\text { treatment recommendations may be adapted in this group. }\end{array}$ & II & C \\
\hline 4.1 .9 & & $\begin{array}{l}\text { Duration of treatment in patients receiving } 2 \text { nd line treatment with tumors showing PR/SD, } \\
\text { treatment could be continued till disease progression or unacceptable toxicity, especially in patients } \\
\text { receiving irinotecan based treatment, or de-escalated especially in patients receiving oxaliplatin } \\
\text { containing treatment. }\end{array}$ & 1 & B \\
\hline 4.1 .10 & & $\begin{array}{l}\text { Monitoring of treatment efficacy with radiological studies should be carried out every } 3 \text { months of } \\
\text { treatment. }\end{array}$ & II & C \\
\hline \multicolumn{5}{|c|}{ Recommendation 4.2. Molecular testing before initiating $2^{\text {nd }}$ line treatment. } \\
\hline 4.2.1 & Restricted. & Molecular profiling is not required for treatment planning in facilities with restricted resources. & II & C \\
\hline 4.2 .2 & $\begin{array}{l}\text { Non- } \\
\text { restricted. }\end{array}$ & $\begin{array}{l}\text { Complementary biomarkers panel required for planning treatment after progression on Ist line } \\
\text { should include Her2, other markers should be requested if not previously done. }\end{array}$ & II & B \\
\hline 4.2 .3 & $\begin{array}{l}\text { Non- } \\
\text { restricted. }\end{array}$ & $\begin{array}{l}\text { Comprehensive genomic testing may be considered in some health care facilities, if resources } \\
\text { allowed. }\end{array}$ & II & B \\
\hline 4.2 .4 & $\begin{array}{l}\text { Non- } \\
\text { restricted. }\end{array}$ & Re-biopsy for patients with previously known RAS status is not required. & II & B \\
\hline \multicolumn{5}{|c|}{ Recommendation 4.3. Adding biological agents to chemotherapy backbone in second line. } \\
\hline 4.3.1 & $\begin{array}{l}\text { Non- } \\
\text { restricted. }\end{array}$ & $\begin{array}{l}\text { For patients who progressed on an anti-EGFR based combination at first line, continuations beyond } \\
\text { progression as well as switching to another anti-EGFR is strongly discouraged. }\end{array}$ & 1 & $A$ \\
\hline 4.3 .2 & $\begin{array}{l}\text { Non- } \\
\text { restricted. }\end{array}$ & $\begin{array}{l}\text { Aflibercept/ramucirumab and continuation of bevacizumab beyond progression +FOLOFIRI are } \\
\text { valid options in patients with PFS more than 3-4 months. }\end{array}$ & I & B \\
\hline 4.3 .3 & $\begin{array}{l}\text { Non- } \\
\text { restricted. }\end{array}$ & $\begin{array}{l}\text { Aflibercept or ramucirumab +FOLFIRI are preferred options in patient with PFS less than 3-4 } \\
\text { months of treatment with first line containing bevacizumab in irinotecan naïve patients. }\end{array}$ & III & B \\
\hline 4.3.4 & $\begin{array}{l}\text { Non- } \\
\text { restricted. }\end{array}$ & $\begin{array}{l}\text { In patient with RAS wild disease who progressed on first line containing Anti-VEGF, anti-EGFR } \\
+ \text { FOLFIRI is an acceptable regimen. }\end{array}$ & II & B \\
\hline
\end{tabular}

(Continued) 
Table 5 (Continued).

\begin{tabular}{|c|c|c|c|c|}
\hline 4.3.5 & $\begin{array}{l}\text { Non- } \\
\text { restricted. }\end{array}$ & $\begin{array}{l}\text { Patients who received Anti-EGFR during } \mathrm{I}^{\text {st }} \text { line and wish to continue on intensified treatment } \\
\text { could be offered Anti-VEFG (beva,rami,Aflib). }\end{array}$ & I & A \\
\hline \multicolumn{5}{|c|}{ Recommendation 4.4: Third line systemic treatment. } \\
\hline 4.4.1 & General. & $\begin{array}{l}\text { For patients who experienced disease progression after two lines of chemotherapy containing } \\
\text { oxaliplatin and irinotecan, the aim of treatment should be to improve tumor related symptoms, } \\
\text { maintain quality of life and to prolong survival (ranked according to priority). }\end{array}$ & I & A \\
\hline 4.4 .2 & General. & $\begin{array}{l}\text { Criteria defining patient eligibility for treatment beyond second line are: } \\
\text { - PS 0-I. } \\
\text { - Maintained adequate kidney/liver function. }\end{array}$ & II & A \\
\hline 4.4 .3 & General. & Treatment should continue till disease progression or unacceptable toxicity. & I & A \\
\hline 4.4 .4 & $\begin{array}{l}\text { Restricted } \\
\text { resources. }\end{array}$ & $\begin{array}{l}\text { For treatment of patients who progressed after oxaliplatin and irinotecan containing regimens,BSC } \\
\text { is the preferred option, these regimens are considered acceptable treatment options as well: } \\
\text { - Single agent irinotecan if the patient received FORLIRI at least } 3 \text { from initiating third line. } \\
\text { - Rechallenge or reintroduction of previously used agents in patients showed response to this } \\
\text { treatment and long duration elapsed since last administration. } \\
\text { - Capecitabine single agent. } \\
\text { - IROX in selected patients. }\end{array}$ & III & C \\
\hline 4.4 .5 & $\begin{array}{l}\text { Non- } \\
\text { restricted } \\
\text { resources. }\end{array}$ & $\begin{array}{l}\text { For patients with wild KRAS/NRAS who experienced progression on therapies not including anti- } \\
\text { EGFR, cetuximab or panitumumab as a single agent or in combination with irinotecan is } \\
\text { recommended.I }\end{array}$ & I & A \\
\hline 4.4 .6 & $\begin{array}{l}\text { Non- } \\
\text { restricted } \\
\text { resources. }\end{array}$ & $\begin{array}{l}\text { Reintroduction of anti-EGFR in third line may be considered in patients with more than } 6 \text { months } \\
\text { after last anti-EGFR administration with response to treatment in first line. }\end{array}$ & II & B \\
\hline 4.4 .7 & $\begin{array}{l}\text { Non- } \\
\text { restricted } \\
\text { resources. }\end{array}$ & $\begin{array}{l}\text { In absence of evidence supporting benefit of single agent bevacizumab, Ziv-aflibercept or } \\
\text { ramucirumab as a third line treatment, it should not be recommended. }\end{array}$ & II & A \\
\hline 4.4 .8 & $\begin{array}{l}\text { Non- } \\
\text { restricted } \\
\text { resources. }\end{array}$ & $\begin{array}{l}\text { Regorafinib and trifluridine-tipiracil (TAS-102) are both valid options for treatment of patients } \\
\text { refractory to chemotherapy. }\end{array}$ & I & A \\
\hline 4.4 .9 & $\begin{array}{l}\text { Non- } \\
\text { restricted } \\
\text { resources. }\end{array}$ & $\begin{array}{l}\text { No evidence to support specific sequence of treatment, however, the panel preferable sequence is } \\
\text { TAS- } 102 \text { then regorafinib. }\end{array}$ & II & B \\
\hline 4.4.10 & $\begin{array}{l}\text { Non- } \\
\text { restricted } \\
\text { resources. }\end{array}$ & $\begin{array}{l}\text { The starting dose of regorafinib should be } 80 \mathrm{mg} / \mathrm{d} \text { continuously with weekly dose escalation to } \\
160 \mathrm{mg} / \mathrm{d} \text { if well tolerated. }\end{array}$ & $\|$ & B \\
\hline 4.4.7 & $\begin{array}{l}\text { Non- } \\
\text { restricted } \\
\text { resources. }\end{array}$ & $\begin{array}{l}\text { In view of recent RCT BEACON CRC, Encorafinib + antiEGFR is recommended for patients with } \\
\text { BRAF V600E mutation who were not previously treated with anti-EGFR. }\end{array}$ & II & C \\
\hline 4.4.7 & $\begin{array}{l}\text { Non- } \\
\text { restricted } \\
\text { resources. }\end{array}$ & $\begin{array}{l}\text { Pembrolizumab, nivolumab or nivolumab plus ipilumumab are acceptable treatment options for } \\
\text { patients failed 2-4 previous lines of chemotherapy with MSI-H tumors. }\end{array}$ & II & A \\
\hline 4.4 .7 & $\begin{array}{l}\text { Non- } \\
\text { restricted } \\
\text { resources. }\end{array}$ & $\begin{array}{l}\text { Her2 targeting agents could be considered in patients with Her2 over expression, heavily } \\
\text { pretreated. }\end{array}$ & II & A \\
\hline
\end{tabular}


Table 6 External Review Board Voting on Level of Agreement and Applicability of EFMS Restricted Resources Recommendations in Each Country

\begin{tabular}{|c|c|c|c|c|c|c|c|c|c|c|}
\hline \multirow[t]{2}{*}{ Recommendation } & \multirow{2}{*}{$\begin{array}{c}\text { Level of } \\
\text { Agreement } \\
\text { ******** }\end{array}$} & \multicolumn{3}{|c|}{ Sudan } & \multicolumn{3}{|c|}{ Tunisia } & \multicolumn{3}{|c|}{ Morocco } \\
\hline & & Applicable. & $\begin{array}{c}\text { Not } \\
\text { Applicable }\end{array}$ & $\begin{array}{c}\text { Applicable in } \\
\text { Some } \\
\text { Centers }\end{array}$ & Applicable & $\begin{array}{c}\text { Not } \\
\text { Applicable }\end{array}$ & $\begin{array}{c}\text { Applicable in } \\
\text { Some } \\
\text { Centers }\end{array}$ & Applicable & $\begin{array}{c}\text { Not } \\
\text { Applicable }\end{array}$ & $\begin{array}{c}\text { Applicable in } \\
\text { Some } \\
\text { Centers }\end{array}$ \\
\hline 1.5.1 & 5 & - & & & - & & & $\bullet$ & & \\
\hline 1.5 .2 & 5 & $\bullet$ & & & $\bullet$ & & & $\bullet$ & & \\
\hline 2.1 .1 & 5 & & & $\bullet$ & $\bullet$ & & & & & $\bullet$ \\
\hline 2.1 .4 & 5 & & & $\bullet$ & $\bullet$ & & & & & • \\
\hline 2.4 .2 & 5 & & - & & & • & & & • & \\
\hline 2.6 .8 & 5 & & & $\bullet$ & & & $\bullet$ & $\bullet$ & & \\
\hline 2.6 .9 & $5^{*}$ & • & & & • & & & $\bullet$ & & \\
\hline 3.1 .6 & 4 & & $\bullet$ & & & $\bullet$ & & & & • \\
\hline 3.2 .4 & 3.3 & & $\bullet$ & & $\bullet$ & & & $\bullet$ & & \\
\hline 3.2 .5 & $3.2^{* *}$ & & & $\bullet$ & - & - & - & - & - & - \\
\hline 3.2 .6 & 4.6 & & & $\bullet$ & $\bullet$ & & & $\bullet$ & & \\
\hline 3.2 .7 & 4.3 & $\bullet$ & & & $\bullet$ & & & $\bullet$ & & \\
\hline 3.3 .1 & 5 & $\bullet$ & & & $\bullet$ & & & $\bullet$ & & \\
\hline 3.3 .2 & 5 & $\bullet$ & & & $\bullet$ & & & $\bullet$ & & \\
\hline 3.3.3 & 5 & $\bullet$ & & & $\bullet$ & & & $\bullet$ & & \\
\hline 4.1.1 & $5^{* * *}$ & • & & & $\bullet$ & & & $\bullet$ & & \\
\hline 4.1 .5 & 4.8 & $\bullet$ & & & $\bullet$ & & & $\bullet$ & & \\
\hline 4.1 .7 & 4.8 & • & & & $\bullet$ & & & $\bullet$ & & \\
\hline 4.1 .9 & 5 & $\bullet$ & & & $\bullet$ & & & $\bullet$ & & \\
\hline 4.2 .1 & 4 & $\bullet$ & & & & $\bullet$ & & & $\bullet$ & \\
\hline 4.4 .1 & 5 & • & & & $\bullet$ & & & $\bullet$ & & \\
\hline 4.4.2 & $5 * * * *$ & $\bullet$ & & & $\bullet$ & & & $\bullet$ & & \\
\hline 4.4 .3 & 5 & $\bullet$ & & & $\bullet$ & & & $\bullet$ & & \\
\hline 4.4 .4 & $3.6^{* * * * * * *}$ & $\bullet$ & & & $\bullet$ & & & $\bullet$ & & \\
\hline
\end{tabular}

Notes: *Approved with a concern about toxicity, **approved with a concern about toxicity, ***panel recommended adding "with no residual toxicity" to the recommendation, ***** panel advised to include patients with PS II as eligible to treatment beyond second line, ******the panel advised to exclude IROX of the treatment options, $* * * * * *$ level of recommendations as defined in Table I, the recommendation was considered a reached consensus if the mean level of agreement was $\geq 4.5$, near consensus 3-4.4, the recommendation was considered rejected if the mean level of agreement was $\leq 2.9$.

elder patients (above 70 years old) with LT sided RAS wild tumors as an acceptable option based on data from a Phase II trial (PANDA trial). ${ }^{36}$

\section{Sector 2: Local Interventions in Patients with $\mathrm{mCRC}$ and the Role of Systemic Chemotherapy Combined with Surgery}

In sector 2, the panel tried to offer answers to questions about the role of local interventions in mCRC patients, when to use these interventions and for which patient.

The panel recommends MDT consultation for patients with oligometastatic disease as previously defined (Recommendation 1.3.5) and for patients with solitary site metastatic involvement "lung, liver or peritoneum". If access to MDT is not possible, refer patients to a health care facility with experienced MDT to be evaluated. If complete resection with pathologically free margins is not possible, resection should not be attempted. ${ }^{37}$

Local interventions including surgery could be offered to patients as a palliative measure or as a radical treatment with curative intent. The local interventions including RFA, TACE, and SBRT can offer long-term control for patients with a localized disease or small tumor burden "Oligometastatic disease".

Organ-specific criteria for selecting patients with metastatic disease amenable for metastasectomy were approved by the surgery expert panel (Table 3, recommendation 2.3). Besides technical surgical criteria, patient and tumor characteristics should be evaluated before deciding the proper sequence of treatment modalities.

In selected patients, liver metastases resection can improve survival significantly with a 5-year median survival rate of $40 \%$ reported in some trials. ${ }^{38}$ Fong's criteria are used to select candidates for curative resection. ${ }^{38}$ 
Based on oncological criteria, patients with resectable mCRC should be further classified into 1) patients with good oncological prognostic criteria 2) patients with an uncertain oncological outcome, 3) patients with a poor oncological outcome (Recommendations 2.2.1, 2.2.2, 2.2.3).

Long-term follow-up data from EORTC 40983 trial did not show a benefit in OS from the addition of perioperative chemotherapy to surgery. ${ }^{39}$ The majority of patients in the EORTC 40983 trial had metachronous metastases (66\%) with relatively long DFS after primary treatment. The panel agreed that the benefit of perioperative chemotherapy for patients with good oncological criteria is controversial; surgery should be the upfront modality. Adjuvant chemotherapy after R0 resection in this group of patients is not recommended as well.

Patients with synchronous metastatic disease are considered of "uncertain oncological outcome", with short OS after resection compared to patients with a metachronous disease. ${ }^{40}$ BRAF mutant tumors are of poor prognosis with a limited benefit of metastasectomy, but it is not considered an absolute contraindication for surgery. ${ }^{41}$ For these patients, perioperative chemotherapy is preferred in patients with initially resectable metastases. If a patient with uncertain oncological criteria or poor prognostic oncological criteria was submitted to surgery, the panel suggests adjuvant chemotherapy with FOLFOX/XELOX in this subset of patients. The JCOG0603 study results presented during ASCO 2020 showed significant improvement in DFS with the addition of adjuvant chemotherapy with no improvement in OS, patients with synchronous metastases represented $54 \%$ of the study population. On subgroup analysis, patients with a synchronous disease showed better DFS compared to metachronous disease. ${ }^{42}$

The role of biologics (Anti-EGFR, Anti-VEGF) patients with resectable metastases is not proven with even detrimental effects in some trials, ${ }^{43}$ thus it is not recommended as a part of peri-operative or adjuvant treatment. ${ }^{44}$

The definition of "potentially resectable" metastatic disease is based mainly on consensus recommendations. ${ }^{37}$ The surgical expert panel agreed on organ-specific criteria for considering patients "potentially resectable" (Recommendations 2.3.2, 2.3.4, 2.3.6, Table 2). Systemic treatment, in this case, is recommended to allow R0 resection. The choice of conversion therapy depends mainly on the molecular profile of the tumor (recommendation 2.6.1, Table 3).

FOLFOX, FOLFIRI are acceptable options as a conversion therapy in restricted resources and as a chemotherapy backbone in non-restricted resources, FOLFOXIRI with or without targeted agents could be an option in selected patients. ${ }^{45,46}$ The panel has major concerns on the toxicity of FOLFOXIRI as conversion therapy and recommends it should be limited to restricted resources if access to targeted agents is not possible in selected patients with excellent PS.

In patients with RAS/BRAF wild tumors, anti-EGFR should be added even in restricted resources to improve the chances of R0 resection regardless of sidedness of the primary tumor.

The role of sidedness in selecting targeted therapy is controversial. NCCN guidelines restrict the administration of anti-EGFR to left-sided tumors ${ }^{47}$ while Pan-Asian adapted ESMO guidelines recommend anti-EGFR in these patients regardless of sidedness. ${ }^{16}$ The panels choose to adopt the pan-Asian adapted ESMO recommendation based on superior ORR favoring anti-EGFR in a meta-analysis of 3 studies with head-to-head comparison of anti-EGFR vs anti-VEGF. ${ }^{48}$

There was a debate on the value of bevacizumab as a treatment option in patients with right-sided RAS/BRAF wild tumors, the panel agreed on adding this regimen as a treatment option with reservations but with a level III of agreement, and it is considered as a less favorable option.

For RAS mutant tumors, doublet or triplet chemotherapy is acceptable with the addition of bevacizumab in nonrestricted resources. In patients with BRAF mutant tumors, FOLFOXIRI plus bevacizumab is an acceptable treatment option. After R0 resection, no evidence supports the continuation of biologics.

\section{Sector 3: Initial (First Line) Systemic Chemotherapy for Metastatic Colorectal Cancer, Resection is Not a Goal}

When surgical resection is not the goal, factors guiding treatment choice should include: the molecular profile, sidedness, patient preference, patient motivation, and expected toxicity. How to use these factors to tailor treatment for each patient in different resource groups and what is the minimal acceptable level of cancer care to be offered in restricted resources centers were the main questions in this sector (Table 4). 
Molecular profile and sidedness are the main factors used as predictive markers for response to targeted therapy with no specific role in selecting chemotherapy. The panel of essential biomarkers should be guided by the resource group to avoid unnecessary costs. The panel agreed on the necessity of extended RAS testing in any resource group as a predictive marker for response to Anti-EGFR agents. ${ }^{49}$ There was a debate on adding BRAF testing in restricted resources, the voting results approved extended RAS/BRAF as an essential panel in restricted resources, with BRAF test used as a negative predictive biomarker denoting resistance to Anti-EGFR. ${ }^{50}$ This recommendation was added to guide decisionmaking in some institutions with restricted resources as well as non-profit patient support organizations sponsoring targeted agents in selected patients with criteria specific to each facility. (Recommendation 3.1.6, Table 4). In the nonrestricted resources group, the panel agreed on adding MSI testing to the previous panel.

The panel agreed that in absence of strong evidence, patients with Her2 amplified RAS/BRAF wild tumors should be treated as RAS/BRAF wild tumors in the first line, thus Her2 testing is not recommended.

Tumor localization or "sidedness" is considered a predictive factor for response to anti-EGFR in the first line as suggested by retrospective analysis of clinical trials. ${ }^{51,52}$ No predictive markers are available for anti-VEGF or chemotherapy efficacy.

FOLFOX, FOLFIRI, XELOX, and FOLFOXIRI are all valid options as chemotherapeutic regimens in the restricted resources group or as a backbone with the addition of targeted therapy in non-restricted resources in fit patients willing to receive intensified therapy. In a meta-analysis for trials comparing FOLFOXIRI to FOLFIRI, higher response rates and better PFS with FOLFOXIRI was reported with a higher incidence of GIII/IV adverse events mainly neutropenia and diarrhea, ${ }^{53}$ FOLFOXIRI should be used with caution and only in facilities with supportive care units. ${ }^{54}$

The panel approved the current guidelines' recommendations against the use of oral fluoropyrimidines in combination with irinotecan with reservation (level of agreement III). The reservation is based on a meta-analysis evaluating CAPIRI/ XELIRI with or without bevacizumab compared to FOLFIRI, no significant difference in the incidence of adverse events was noted. ${ }^{55}$

The maintenance treatment in restricted resources is controversial; limited benefit in PFS and absence of OS are the main criticism points to this treatment strategy. ${ }^{56}$ Based on data from Two trials (OPTIMOX and CONcePT) evaluated the withdrawal and reintroduction of oxaliplatin upon progression with the maintenance with $5 \mathrm{FU}$ or capecitabine. ${ }^{57,58}$ The recommendation approved was maintenance treatment with 5FU or capecitabine. (Recommendation 3.2.7, level of agreement II, Recommendation type B).

In non-restricted resources, treatment choice is based on molecular profile and sidedness. Patients fit for intensified treatment should be classified into RAS/BRAF wild left-sided tumors, RAS/BRAF wild right-sided tumors, BRAF mutant tumors regardless of sidedness, and patients with MSI-H tumors.

In RAS/BRAF wild left-sided tumors, FOLFOX or FOLFIRI in combination with anti-EGFR is the preferred option based on benefit in OS. ${ }^{52}$ Capecitabine-based and 5FU bolus chemotherapy backbone is not recommended in combination with anti-EGFR due to reduced efficacy. ${ }^{33}$

In RAS/BRAF wild right-sided and RAS mutant tumors, FOLFOX, FOLFIRI, and XELOX in combination with bevacizumab is the preferred treatment choice. The main benefit of bevacizumab is offering clinical benefit in terms of PFS with no OS benefit. ${ }^{59}$

For BRAF mutant patients, doublet or triplet chemotherapy in combination with bevacizumab are all acceptable options. The updated results of TRIBE2 trial showed a potential benefit of FOLFOXIRI plus bevacizumab in a small subgroup of patients with BRAF mutation. ${ }^{60}$ In this subset of patients, triplet chemotherapy with bevacizumab in fit patients is the preferred option. The ANCHOR trial is ongoing investigating the role of adding BRAF inhibitor (encorafenib) in the first line. ${ }^{61}$

For MSI-H tumors, pembrolizumab showed significant improvement in PFS and response rates as first-line treatment. ${ }^{62}$ Single agent pembrolizumab presents an acceptable option, with long-term follow-up and OS data still pending.

Intensified treatment with triplet chemotherapy (FOLFOXIRI) combined with panitumumab was evaluated in phase II trial VOLFI, a numerical trend towards improved OS was noted. ${ }^{63}$ The panel prefers waiting for more solid and longterm data before approving this treatment option, currently, it is not recommended. 
For patients fit to less intensified treatment as defined in sector 1, treatment options in restricted resources include capecitabine single agent, FOLFOX/FOLFIRI with reduced dose according to PS and comorbidities. Patients under single agent capecitabine should be under treatment till disease progression or unacceptable toxicity.

In non-restricted resources, the panel adopted the currently available treatment options (Capecitabine/bevacizumab continued till disease progression or unacceptable toxicity) based on efficacy and safety data reported in AVEX trial in elderly patients above 70 years old not candidates for intensified therapy. ${ }^{64,65}$

In patients receiving CAPOX-bevacizumab as induction therapy, de-escalation of chemotherapy and maintenance with CAP/Beva is recommended. ${ }^{64}$

\section{Sector 4: Systemic Treatment in the Second Line and Beyond}

One of the most challenging clinical situations in restricted resources setting is the management of patients progressing on prior line of treatment. In sector 4, questions about the proper sequence of treatment and potential treatment options in later lines were discussed (Table 5).

Patients who received FOLFOX as initial treatment can receive FOLFIRI upon progression and vice-versa. ${ }^{66}$ Irinotecan single agent may represent a treatment option in patients not eligible for FOLFIRI using the same criteria to define treatment intensity in the first line, but it should not be considered in fit patients due to inferior efficacy compared to a combination. ${ }^{67}$ For patients who received first-line treatment with FOLFOXIRI, no clear evidence-based treatment options are available; the panel suggests these patients to be treated with treatment options approved for the third line.

The duration of treatment in patients receiving chemotherapy as the second line is not well defined, the panel agrees on either de-escalation in form of oxaliplatin withdrawal in patients receiving FOLFOX/XELOX or continuation without de-escalation in patients receiving FOLFIRI. Pre-defined treatment duration is also an acceptable option.

No additional molecular biomarkers are needed for treatment planning in the second line in restricted resources. For non-restricted resources, additional testing for Her2 overexpression ${ }^{68}$ could be considered besides RAS/BRAF/MSI if not tested before the first line. Comprehensive genetic profiling may be considered in some institutions according to their inner fund policies.

No Phase III head-to-head trials were conducted to compare anti-EGFR to anti-VEGF in the second line, one phase II randomized trial showed comparable efficacy in terms of PFS and OS in patients with wild RAS. ${ }^{69}$

Efficacy of anti-EGFR /FOLFIRI in the second line showed limited benefit in PFS and no improvement in OS compared to chemotherapy alone. ${ }^{70,71}$ The predictive value of sidedness in choosing one targeted agent over another is not confirmed in second-line treatment with data from retrospective analysis suggesting better results when limiting the use of anti-EGFR to left-sided tumors. ${ }^{72}$ The panel considers anti-EGFR in the second line as a less preferable option, and to be limited to patients with left-sided tumors progressing on initial treatment with FOLFOX/XELOX with bevacizumab with RAS/BRAF wild tumors.

In patients treated initially with FOLFIRI and bevacizumab naïve, bevacizumab plus FOLFOX is a preferable treatment option. ${ }^{73}$ In patients not previously exposed to irinotecan treated with FOLFOX as initial treatment, FOLFIRI plus aflibercept is a valid treatment option with improvement in OS by 1.8 months. ${ }^{74,75}$ Ramucirumab is also another option that could be considered in combination with FOLFIRI. ${ }^{76}$

In patients treated with bevacizumab at the first line, the panel discussed the treatment options including the continuation of bevacizumab beyond progression or switching to other anti-angiogenetic agents. The panel chose to adopt the ESMO recommendation of switching to aflibercept or ramucirumab plus FOLFIRI in rapid progressor patients defined as those progressing within less than 3-4 months of bevacizumab treatment in the first line. ${ }^{16,33}$ The recommendation was approved by level of agreement III.

In restricted resources, the panel emphasizes the absence of evidence-based treatment options in patients who progressed on oxaliplatin and irinotecan-based treatments and considers best supportive care as the preferred modality. Treatment options for patients with maintained good PS and willing to receive active treatment are summarized in recommendation 4.4.4. The panel considers single-agent irinotecan in patients who did not recently receive irinotecan- 
based treatment, re-challenge with previously used regimens in earlier treatment lines, capecitabine as a single agent and IROX but as the least favorable treatment option with concerns on toxicity.

In non-restricted resources, the panel adopts international guidelines on considering both regorafenib and trifluridine/ tipiracil (TAS-102) as acceptable treatment options in the third line, ${ }^{16,33,47}$ with TAS-102 then regorafenib as the preferred sequence if the patient is still amenable for active treatment.

In patients with RAS/BRAF wild tumors who were never exposed to Anti-EGFR treatment, anti-EGFR agents could be considered in the third line as a single agent. ${ }^{77,78}$ Reintroduction of anti-EGFR may be a reasonable option in patients who received anti-EGFR in first-line and exhausted previous lines of treatment, provided that more than 6 months after last anti-EGFR administration with response to treatment in the first line. ${ }^{79-81}$

Other treatment options are now available including encorafenib/cetuximab in RAS wild BRAF mutant patients, ${ }^{82}$ Her2 targeting agents in patients with Her2 overexpression (trastuzumab plus lapatinib, ${ }^{83}$ trastuzumab plus pertuzumab $^{84}$ or trastuzumab deruxtecan ${ }^{85}$ ), and immunotherapy (single-agent nivolumab ${ }^{86}$ or pembrolizumab ${ }^{87}$ nivolumab plus ipilimumab combination ${ }^{88}$ ). More phase III studies are required before considering these treatments as a standard of care. In heavily pre-treated patients, the main benefit of these agents was either improvement in response rates (RR) or in PFS.

\section{External Review Board Voting}

EFMS recommendations were assessed for applicability in low and lower-middle income countries in North Africa (Tunisia, Morocco and Sudan).

Recommendations were accepted with variable levels of agreement by external review board members (Table 6). Applicability varied between countries even within the same income group.

Proposed recommendations on defining treatment intensity in restricted resources as well as recommendations on principles of management for patients with Oligometastatic disease were accepted and applicable in all countries. SBRT plus FOLFIRI was agreed upon by all the review board, but not applicable in most countries due to lack of infrastructure.

Experts from Tunisia and Morocco asked to add a recommendation on routine DPD testing, DPD testing is performed as a routine test for all patients before initiating treatment with 5FU/capecitabine in Tunisia, while in Morocco it is performed in patients showing toxicity pattern suggestive of DPD deficiency as in Egypt. DPD test is available in very limited centers in Sudan.

Adding Anti-EGFR to chemotherapy backbone in RAS wild patients with potentially resectable tumors regardless of sidedness even in restricted resources was approved by the entire panel. However, access to Anti-EGFR is very limited in Sudan, FOLFOXIRI is considered more applicable as a conversion treatment option.

Adding BRAF to extended RAS test as a basic molecular profile before initiating first line treatment was also discussed. BRAF test is not sponsored in Tunisia and thus it is not performed routinely. Access to BRAF test is available in some centers in Morocco but not considered a standard of care.

The idea of intensifying chemotherapy with triplets in restricted resources was not agreed upon due to concerns on toxicity, triplets should be limited only to patients with PS 0 symptomatic patients with high tumor burden.

The concept of maintenance treatment instead of a total treatment breakdown was preferred by all the external panel members. However, each center should sort out the priorities and internal policies with priority to patients treated for cure in early stages. If resources are enough to give both, maintenance should be considered. If not, priority should be given to curative and early disease.

The panelists commented on restricting second line and beyond to patients with PS $0-11$, they prefer offering treatment to patients with PS II with no residual toxicity from prior lines.

For third line, they highlighted the fact of absence of approved third line treatment options (trifluridine/tipiracil and regorafenib) from most facilities. Other suggested treatment options were accepted except IROX, due to toxicity concerns and absence of data on efficacy in later lines. 


\section{Conclusion}

Colorectal cancer is a major health problem in Egypt and around the world. ${ }^{89}$ EFMS developed these recommendations to be convenient with the Egyptian healthcare system, bearing in mind the complexity, fragmentation, and heterogeneity of health care policies between different facilities and institutions in Egypt.

The main limitation of this recommendation is the absence of cost-effectiveness studies for most therapeutic interventions. The grouping into restricted and non-restricted was based on availability and reimbursement policies of targeted agents. The absence of national data on some clinically important points (eg incidence of DPD deficiency) hurdled the development of recommendations for these points. Lack of clinical audit policies will pose a considerable challenge to assess and measure the impact of implementing the current recommendations.

The current recommendations highlighted the discrepancy in health care between restricted and non-restricted resources with expected survival loss and quality of life deterioration. Access to targeted agents in the first line is very limited, and access gets more limited at later lines of treatment.

Recommendations for treatment in the third line in restricted resources are all approved with level III approval due to concerns on efficacy and expected toxicity, all of them are between type $\mathrm{B}$ or type $\mathrm{C}$ based on a low level of evidence, eg IROX, ${ }^{90}$ or based solely on expert opinion. With increased incidence among patients less than 45 years old. Patients with refractory disease failed on irinotecan and oxaliplatin-based treatment with maintained good PS and willing to receive active treatment is not an uncommon scenario. The current expanding treatment landscape will not be accessible to the majority of patients.

Heterogeneity in health care policies and available resources is noted even in the same country and between countries within the same income range. The lack of clinical practice recommendations tailored according to local status led to wide diversity of clinical care decisions offered to patients and with no supporting evidence. The need to harmonize clinical care options within each country is mandatory. National adaptation of international guidelines with variable degrees is an option to close possible gaps not covered by international guidelines.

The current consensus recommendations could be adopted and generalized in other countries with similar economic and health care status, as an example for management in middle low-income countries. External review by target consumers after dissemination and implementation is planned, aiming to guide the next version of the EFMS consensus recommendations.

\section{Funding}

This work was sponsored and funded by Sanofi (Biopharmaceutical company) and Servier Laboratories (pharmaceutical company). Sanofi and Servier did not influence the content of the manuscript, nor did the panelists or authors receive financial compensation for authoring this manuscript.The companies sponsored the multiple meetings (physical and virtual, without attending them nor accessing any record of discussed topics), medical writing and publications fees.

\section{Disclosure}

Dr Loay Kassem reports personal fees from Roche, Novartis, Amgen, Pfizer, Sandoz, and Lilly, outside the submitted work. The authors declare that they have no other known competing financial interests or personal relationships that could have appeared to influence the work reported in this paper.

\section{References}

1. Sung H, Ferlay J, Siegel RL, et al. Global Cancer Statistics 2020: GLOBOCAN Estimates of Incidence and Mortality Worldwide for 36 Cancers in 185 Countries. CA Cancer J Clin. 2021 ;71(3):209-249. doi: 10.3322/caac.21660.

2. Lykoudis PM, O’Reilly D, Nastos K, Fusai G. Systematic review of surgical management of synchronous colorectal liver metastases. Br J Surg. 2014;101(6):605-612. doi:10.1002/bjs.9449

3. Nordlinger B, Van Cutsem E, Rougier P, et al. Does chemotherapy prior to liver resection increase the potential for cure in patients with metastatic colorectal cancer? A report from the European Colorectal Metastases Treatment Group. Eur J Cancer. 2007;43(14):2037-2045. doi:10.1016/j. ejca.2007.07.017

4. Ibrahim AS, Khaled HM, Mikhail NN, Baraka H, Kamel H. Cancer incidence in Egypt: results of the national population-based cancer registry program. J Cancer Epidemiol. 2014;2014:1-18. doi:10.1155/2014/437971

5. Metwally IH, Shetiwy M, Elalfy AF, Abouzid A, Saleh SS, Hamdy M. Epidemiology and survival of colon cancer among Egyptians: a retrospective study. J Coloproctol. 2018;38(1):24-29. doi:10.1016/j.jcol.2017.09.418 
6. Grothey A, Sargent D, Goldberg RM, Schmoll HJ. Survival of patients with advanced colorectal cancer improves with the availability of fluorouracil-leucovorin, irinotecan, and oxaliplatin in the course of treatment. J Clin Oncol. 2004;22(7):1209-1214. doi:10.1200/JCO.2004.11.037

7. Asmis T, Berry S, Cosby R, Chan K, Coburn N, Rother M. Strategies of sequential therapies in unresectable metastatic colorectal cancer: a meta-analysis. Curr Oncol. 2014;21(6):318-328. doi:10.3747/co.21.2146

8. Heinemann V, Von Weikersthal LF, Decker T, et al. FOLFIRI plus cetuximab versus FOLFIRI plus bevacizumab as first-line treatment for patients with metastatic colorectal cancer (FIRE-3): a randomised, open-label, Phase 3 trial. Lancet Oncol. 2014;15(10):1065-1075. doi:10.1016/S14702045(14)70330-4

9. Venook AP, Niedzwiecki D, Lenz HJ, et al. Effect of first-line chemotherapy combined with cetuximab or bevacizumab on overall survival in patients with KRAS wild-type advanced or metastatic colorectal cancer a randomized clinical trial. JAMA. 2017;317(23):2392-2401. doi:10.1001/ jama.2017.7105

10. Piedbois P. Efficacy of intravenous continuous infusion of fluorouracil compared with bolus administration in advanced colorectal cancer. $J$ Clin Oncol. 1998;16(1):301-308. doi:10.1200/JCO.1998.16.1.301

11. Gabriela Chiorean E, Nandakumar G, Fadelu T, et al. Treatment of patients with late-stage colorectal cancer: ASCO resource-stratified guideline. J Glob Oncol. 2020;6(6):414-438. doi:10.1200/JGO.19.00367

12. Jakovljevic M, Gutzwiller F, Schwenkglenks M, et al. Costs differences among monoclonal antibodies-based first-line Oncology cancer protocols for breast cancer, colorectal carcinoma and non-Hodgkin's lymphoma. J BUON. 2014;19(4):1111-1120. doi:10.5167/uzh-117543

13. Cristina W, Silva D, Martin A, et al. Medical cost of colorectal cancer services in Serbia Between 2014 and 2017: national data report. Natl Data Rep Front Pharmacol. 2019;10:526. doi:10.3389/fphar.2019.00526

14. Kovacevic A, Dragojevic-Simic V, Tarabar D, et al. Five-year survival and costs of care in metastatic colorectal cancer: conventional versus monoclonal antibody-based treatment protocols. Expert Rev Anticancer Ther. 2015;15(8):963-970. doi:10.1586/14737140.2015.1059280

15. Marquet JM. Colon cancer. Oncologie. 1999;1(6):343-347.

16. Yoshino T, Arnold D, Taniguchi H, et al. Pan-Asian adapted ESMO consensus guidelines for the management of patients with metastatic colorectal cancer: a JSMO-ESMO initiative endorsed by CSCO, KACO, MOS, SSO and TOS. Ann Oncol. 2018;29(1):44-70. doi:10.1093/annonc/mdx738

17. German S3-Guideline Colorectal Cancer G. German guideline program in oncology (German Cancer Society, German Cancer Aid, AWMF): S3-Guideline Colorectal Cancer, long version 2.1, 2019, AWMF registrationnumber: 021-007OL; 2019:1-322. Available from: http://www. leitlinienprogramm-onkologie.de/leitlinien/kolorektales-karzinom/. Accessed February 9, 2022.

18. Elizabeth Murphy AH, Freeman V, Barclay K, et al. Cancer Council Australia Colorectal Cancer Guidelines Working Party (2017) PRP2-5, 7: can peri operative management be optimised? Clinical practice guidelines for the prevention, early detection and management of colorectal cancer; 2018. Available from: https://wiki.cancer.org.au/australiawiki/images/e/ed/Colorectal cancer guidelines short form.pdf. Accessed February 9, 2022.

19. Vekic B, Dragojevic-Simic V, Jakovljevic M, et al. A correlation study of the colorectal cancer statistics and economic indicators in selected Balkan Countries. Front Public Health. 2020;8:1-8. doi:10.3389/fpubh.2020.00029

20. Egypt, Arab Rep. | Data. Available from: https://data.worldbank.org/country/EG. Accessed March 12, 2021.

21. Egypt profiles and briefs. EMRO Regional Health Observatory. Available from: https://rho.emro.who.int/per-country-egy. Accessed December 10, 2021.

22. Fervers B, Burgers JS, Voellinger R, et al. Guideline adaptation: an approach to enhance efficiency in guideline development and improve utilisation. BMJ Qual Saf. 2011;20(3):228-236. doi:10.1136/bmjqs.2010.043257

23. Data for Lower middle income, Tunisia| Data. Available from: https://data.worldbank.org/?locations=XN-TN. Accessed September 14, 2021.

24. Morocco | Data. Available from: https://data.worldbank.org/country/MA. Accessed September 14, 2021.

25. Sudan | Data. Available from: https://data.worldbank.org/country/SD. Accessed September 14, 2021.

26. Rosenfeld RM, Nnacheta LC, Corrigan MD. Clinical consensus statement development manual. Otolaryngol Head Neck Surg. 2015;153:S1-S14. doi:10.1177/0194599815601394

27. Nahler G. ECOG performance status. Dict Pharm Med. 2009;60. doi:10.1007/978-3-211-89836-9_452

28. Mohile SG, Dale W, Somerfield MR, Hurria A. Practical assessment and management of vulnerabilities in older patients receiving chemotherapy: Asco guideline for geriatric Oncology summary. J Oncol Pract. 2018;14(7):442-446. doi:10.1200/JOP.18.00180

29. Hurria A, Gupta S, Zauderer M, et al. Developing a cancer-specific geriatric assessment: a feasibility study. Cancer. 2005;104(9):1998-2005. doi:10.1002/cncr.21422

30. Janus N, Thariat J, Boulanger H, Deray G, Launay-Vacher V. Proposal for dosage adjustment and timing of chemotherapy in hemodialyzed patients. Ann Oncol. 2010;21(7):1395-1403. doi:10.1093/annonc/mdp598

31. Funakoshi T, Horimatsu T, Nakamura M, et al. Chemotherapy in cancer patients undergoing haemodialysis: a nationwide study in Japan. ESMO Open. 2018;3(2):1-7. doi:10.1136/esmoopen-2017-000301

32. Guckenberger M, Lievens Y, Bouma AB, et al. Characterisation and classification of oligometastatic disease: a European Society for Radiotherapy and Oncology and European Organisation for Research and Treatment of Cancer consensus recommendation. Lancet Oncol. 2020;21(1):e18-e28. doi:10.1016/S1470-2045(19)30718-1

33. Van Cutsem E, Cervantes A, Adam R, et al. ESMO consensus guidelines for the management of patients with metastatic colorectal cancer. Ann Oncol. 2016;27(8):1386-1422. doi:10.1093/annonc/mdw235

34. Ulanja MB, Rishi M, Beutler BD, et al. Colon cancer sidedness, presentation, and survival at different stages. J Oncol. 2019;2019(Lcc):1-12. doi:10.1155/2019/4315032

35. Folprecht G, Seymour MT, Saltz L, et al. Irinotecan/fluorouracil combination in first-line therapy of older and younger patients with metastatic colorectal cancer: combined analysis of 2691 patients in randomized controlled trials. J Clin Oncol. 2008;26(9):1443-1451. doi:10.1200/ JCO.2007.14.0509

36. Lonardi S, Schirripa M, Buggin F, et al. First-line FOLFOX plus panitumumab versus 5FU plus panitumumab in RAS-BRAF wild-type metastatic colorectal cancer elderly patients: the PANDA study. J Clin Oncol. 2020;38(15_suppl):4002. doi:10.1200/jco.2020.38.15_suppl.4002

37. Adam R, De Gramont A, Figueras J, et al. The oncosurgery approach to managing liver metastases from colorectal cancer: a multidisciplinary international consensus-NICOLAS VAUTHEY OF THE EGOSLIM (EXPERT GROUP ON ONCOSURGERY MANAGEMENT OF LIVER METASTASES) GROUP g Oncologist ${ }^{\circledR}$ Academia-Pharma Intersect: hepatobiliary. Oncologist. 2012;17:1225-1239. doi:10.1634/theoncologist.2012-0121 
38. Choti MA, Sitzmann JV, Tiburi MF, et al. Trends in long-term survival following liver resection for hepatic colorectal metastases. Ann Surg. 2002;235(6):759-766. doi:10.1097/00000658-200206000-00002

39. Nordlinger B, Sorbye H, Glimelius B, et al. Perioperative FOLFOX4 chemotherapy and surgery versus surgery alone for resectable liver metastases from colorectal cancer (EORTC 40983): long-term results of a randomised, controlled, phase 3 trial. Lancet Oncol. 2013;14(12):1208-1215. doi:10.1016/S1470-2045(13)70447-9

40. Tsai M-S, Su Y-H, Ho M-C, et al. Clinicopathological features and prognosis in resectable synchronous and metachronous colorectal liver metastasis. Ann Surg Oncol. 2007;14(2):786-794. doi:10.1245/s10434-006-9215-5

41. Prasanna T, Wong R, Price T, et al. Metastasectomy and BRAF mutation; an analysis of survival outcome in metastatic colorectal cancer. Curr Probl Cancer. 2021;45(1):100637. doi:10.1016/j.currproblcancer.2020.100637

42. Kanemitsu Y, Shimizu Y, Mizusawa J, et al. A randomized phase II/III trial comparing hepatectomy followed by mFOLFOX6 with hepatectomy alone for liver metastasis from colorectal cancer: JCOG0603 study. J Clin Oncol. 2020;38(15_suppl):4005. doi:10.1200/jco.2020.38.15_suppl.4005

43. Stahler A, Heinemann V, Holch JW, et al. Mutational profiles of metastatic colorectal cancer treated with FOLFIRI plus cetuximab or bevacizumab before and after secondary resection (AIO KRK 0306; FIRE-3). Int J Cancer. 2021;149(11):1935-1943. doi:10.1002/ijc.33747

44. Bridgewater JA, Pugh SA, Maishman T, et al. Systemic chemotherapy with or without cetuximab in patients with resectable colorectal liver metastasis (New EPOC): long-term results of a multicentre, randomised, controlled, phase 3 trial. Lancet Oncol. 2020;21(3):398-411. doi:10.1016/ S1470-2045(19)30798-3

45. Masi G, Loupakis F, Pollina L, et al. Long-term outcome of initially unresectable metastatic colorectal cancer patients treated with 5-fluorouracil/ leucovorin, oxaliplatin, and irinotecan (FOLFOXIRI) followed by radical surgery of metastases. Ann Surg. 2009;249(3):420-425. doi:10.1097/ SLA.0b013e31819a0486

46. Tomasello G, Petrelli F, Ghidini M, Russo A, Passalacqua R, Barni S. FOLFOXIRI plus bevacizumab as conversion therapy for patients with initially unresectable metastatic colorectal cancer: a systematic review and pooled analysis. JAMA Oncol. 2017;3(7):1-6. doi:10.1001/ jamaoncol.2017.0278

47. Benson AB, Venook AP, Al-Hawary MM, et al. Colon Cancer Colon Cancer. NCCN Harmon Guidel Sub-Saharan Africa - Colon Cancer. 2018; Version 2. (Colon Cancer):1-5. J Natl Compr Canc Netw. 2018;16(4):359-369.

48. Heinemann V, Rivera F, O'Neil BH, et al. A study-level meta-analysis of efficacy data from head-to-head first-line trials of epidermal growth factor receptor inhibitors versus bevacizumab in patients with RAS wild-type metastatic colorectal cancer. Eur J Cancer. 2016;67:11-20. doi:10.1016/j. ejca.2016.07.019

49. Sepulveda AR, Hamilton SR, Allegra CJ, et al. Molecular biomarkers for the evaluation of colorectal cancer: guideline from the American Society for Clinical Pathology, College of American Pathologists, Association for Molecular Pathology, and American Society of Clinical Oncology. CAP Laboratory Improvement Programs. Am J Clin Pathol. 2017;147(3):221-260. doi:10.5858/arpa.2016-0554-CP

50. Pietrantonio F, Petrelli F, Coinu A, et al. Predictive role of BRAF mutations in patients with advanced colorectal cancer receiving cetuximab and panitumumab: a meta-analysis. Eur J Cancer. 2015;51(5):587-594. doi:10.1016/j.ejca.2015.01.054

51. Boeckx N, Koukakis R, de Beeck KO, et al. Primary tumor sidedness has an impact on prognosis and treatment outcome in metastatic colorectal cancer: results from two randomized first-line panitumumab studies. Ann Oncol. 2017;28(8):1862-1868. doi:10.1093/annonc/mdx119

52. Arnold D, Lueza B, Douillard JY, et al. Prognostic and predictive value of primary tumour side in patients with RAS wild-type metastatic colorectal cancer treated with chemotherapy and EGFR directed antibodies in six randomized trials. Ann Oncol. 2017;28(8):1713-1729. doi:10.1093/annonc/ $\operatorname{mdx} 175$

53. Montagnani F, Chiriatti A, Turrisi G, Francini G, Fiorentini G. A systematic review of FOLFOXIRI chemotherapy for the first-line treatment of metastatic colorectal cancer: improved efficacy at the cost of increased toxicity. Color Dis. 2011;13(8):846-852. doi:10.1111/j.14631318.2010.02206.x

54. Kotani D, Yoshino T, Kotaka M, et al. Combination therapy of capecitabine, irinotecan, oxaliplatin, and bevacizumab as a first-line treatment for metastatic colorectal cancer: safety lead-in results from the QUATTRO-II study. Invest New Drugs. 2021;39(6):1649-1655. doi:10.1007/s10637021-01125-2

55. Guo Y, Shi M, Shen X, Yang C, Yang L, Zhang J. Capecitabine plus irinotecan versus 5-FU/leucovorin plus irinotecan in the treatment of colorectal cancer: a meta-analysis. Clin Colorectal Cancer. 2014;13(2):110-118. doi:10.1016/j.clcc.2013.12.004

56. Berry SR, Cosby R, Asmis T, Chan K, Hammad N, Krzyzanowska MK. Continuous versus intermittent chemotherapy strategies in metastatic colorectal cancer: a systematic review and meta-analysis. Ann Oncol. 2015;26(3):477-485. doi:10.1093/annonc/mdu272

57. de Gramont A, Buyse M, Abrahantes JC, et al. Reintroduction of oxaliplatin is associated with improved survival in advanced colorectal cancer. J Clin Oncol. 2007;25(22):3224-3229. doi:10.1200/JCO.2006.10.4380

58. Hochster HS, Grothey A, Hart L, et al. Improved time to treatment failure with an intermittent oxaliplatin strategy: results of CONcePT. Ann Oncol. 2014;25(6):1172-1178. doi:10.1093/annonc/mdu107

59. Botrel TEA, Clark LG, Paladini L, Clark OA. Efficacy and safety of bevacizumab plus chemotherapy compared to chemotherapy alone in previously untreated advanced or metastatic colorectal cancer: a systematic review and meta-analysis. BMC Cancer. 2016;16(1):1-19. doi:10.1186/ s12885-016-2734-y

60. Cremolini C, Antoniotti C, Rossini D, et al. Upfront FOLFOXIRI plus bevacizumab and reintroduction after progression versus mFOLFOX6 plus bevacizumab followed by FOLFIRI plus bevacizumab in the treatment of patients with metastatic colorectal cancer (TRIBE2): a multicentre, open-label, phase 3, rand. Lancet Oncol. 2020;21(4):497-507. doi:10.1016/S1470-2045(19)30862-9

61. Sunakawa Y, Sakamoto Y, Inoue E, et al. ANCHOR CRC: a single-arm, Phase 2 study of encorafenib, binimetinib plus cetuximab in previously untreated BRAF V600E-mutant metastatic colorectal cancer. Ann Oncol. 2020;31:S242-S243. doi:10.1016/j.annonc.2020.04.078

62. André T, Shiu -K-K, Kim TW, et al. Pembrolizumab in microsatellite-instability-high advanced colorectal cancer. N Engl J Med. 2020;383 (23):2207-2218. doi:10.1056/nejmoa2017699

63. Modest DP, Martens UM, Riera-Knorrenschild J, et al. FOLFOXIRI plus panitumumab as first-line treatment of RAS wild-type metastatic colorectal cancer: the randomized, open-label, Phase II Volfi study (AIO KRK0109). J Clin Oncol. 2019;37(35):3401-3411. doi:10.1200/ JCO. 19.01340 
64. Cunningham D, Lang I, Marcuello E, et al. Bevacizumab plus capecitabine versus capecitabine alone in elderly patients with previously untreated metastatic colorectal cancer (AVEX): an open-label, randomised phase 3 trial. Lancet Oncol. 2013;14(11):1077-1085. doi:10.1016/S1470-2045(13) 70154-2

65. Kosugi C, Koda K, Denda T, et al. Multicenter phase II clinical study of the efficiency and safety of capecitabine plus intermittent oxaliplatin with bevacizumab as first-line therapy in patients with metastatic colorectal cancer (VOICE trial). Int J Colorectal Dis. 2021;36(12):2637-2647. doi: 10.1007/s00384-021-03995-7

66. Tournigand C, André T, Achille E, et al. FOLFIRI followed by FOLFOX6 or the reverse sequence in advanced colorectal cancer: a randomized GERCOR study. J Clin Oncol. 2004;22(2):229-237. doi:10.1200/JCO.2004.05.113

67. Clarke SJ, Yip S, Brown C, et al. Single-agent irinotecan or 5-fluorouracil and leucovorin (FOLFIRI) as second-line chemotherapy for advanced colorectal cancer; Results of a randomised phase II study (DaVINCI) and meta-analysis. Eur J Cancer. 2011;47(12):1826-1836. doi:10.1016/j. ejca.2011.04.024

68. Valtorta E, Martino C, Sartore-Bianchi A, et al. Assessment of a HER2 scoring system for colorectal cancer: results from a validation study. Mod Pathol. 2015;28(11):1481-1491. doi:10.1038/modpathol.2015.98

69. Shitara K, Yonesaka K, Denda T, et al. Randomized study of FOLFIRI plus either panitumumab or bevacizumab for wild-type KRAS colorectal cancer-WJOG 6210G. Cancer Sci. 2016;107:1843-1850. doi:10.1111/cas.13098

70. Sobrero AF, Maurel J, Fehrenbacher L, et al. EPIC: phase III trial of cetuximab plus irinotecan after fluoropyrimidine and oxaliplatin failure in patients with metastatic colorectal cancer. J Clin Oncol. 2008;26(14):2311-2319. doi:10.1200/JCO.2007.13.1193

71. Peeters M, Oliner KS, Price TJ, et al. Analysis of KRAS/NRAS mutations in a Phase III study of panitumumab with FOLFIRI compared with FOLFIRI alone as second-line treatment for metastatic colorectal cancer. Clin Cancer Res. 2015;21(24):5469-5479. doi:10.1158/1078-0432.CCR$15-0526$

72. Boeckx N, Koukakis R, Op de Beeck K, et al. Effect of primary tumor location on second- or later-line treatment outcomes in patients with RAS wild-type metastatic colorectal cancer and all treatment lines in patients with RAS mutations in four randomized panitumumab studies. Clin Colorectal Cancer. 2018;17(3):170-178.e3. doi:10.1016/j.clcc.2018.03.005

73. Giantonio BJ, Catalano PJ, Meropol NJ, et al. Bevacizumab in combination with oxaliplatin, fluorouracil, and leucovorin (FOLFOX4) for previously treated metastatic colorectal cancer: results from the Eastern Cooperative Oncology Group Study E3200. J Clin Oncol. 2007;25 (12):1539-1544. doi:10.1200/JCO.2006.09.6305

74. Van Cutsem E, Tabernero J, Lakomy R, et al. Addition of aflibercept to fluorouracil, leucovorin, and irinotecan improves survival in a phase III randomized trial in patients with metastatic colorectal cancer previously treated with an oxaliplatin-based regimen. J Clin Oncol. 2012;30 (28):3499-3506. doi:10.1200/JCO.2012.42.8201

75. Joulain F, Proskorovsky I, Allegra C, et al. Mean overall survival gain with aflibercept plus FOLFIRI vs placebo plus FOLFIRI in patients with previously treated metastatic colorectal cancer. Br J Cancer. 2013;109(7):1735-1743. doi:10.1038/bjc.2013.523

76. Tabernero J, Yoshino T, Cohn AL, et al. Ramucirumab versus placebo in combination with second-line FOLFIRI in patients with metastatic colorectal carcinoma that progressed during or after first-line therapy with bevacizumab, oxaliplatin, and a fluoropyrimidine (RAISE): a randomised, double-blind, multicentre, phase 3 study. Lancet Oncol. 2015;16(5):499-508. doi:10.1016/S1470-2045(15)70127-0

77. Jonker DJ, O'Callaghan CJ, Karapetis CS, et al. Cetuximab for the treatment of colorectal cancer abstract. Vol 357; 2007. Available from: www. nejm.org. Accessed February 9, 2022.

78. Van Cutsem E, Peeters M, Siena S, et al. Open-label phase III trial of panitumumab plus best supportive care compared with best supportive care alone in patients with chemotherapy- refractory metastatic colorectal cancer. J Clin Oncol. 2007;25(13):1658-1664. doi:10.1200/JCO.2006.08.1620

79. Mauri G, Pizzutilo EG, Amatu A, et al. Retreatment with anti-EGFR monoclonal antibodies in metastatic colorectal cancer: systematic review of different strategies. Cancer Treat Rev. 2019;73:41-53. doi:10.1016/j.ctrv.2018.12.006

80. Karani A, Felismino TC, Diniz L, Petaccia Macedo M, Souza e Silva V, Abdon Mello C. Is there a role for rechallenge and reintroduction of anti-EGFR plus chemotherapy in later lines of therapy for metastatic colorectal carcinoma? A retrospective analysis. Ecancermedicalscience. 2020;14:1-11. doi:10.3332/ecancer.2020.1069

81. GONO. A Phase II single-arm study of cetuximab plus irinotecan as rechallenge 3 Rd -line treatment of metastatic colorectal cancer patients progressing after an initial response to a 1st -line cetuximab-containing therapy and a standard 2nd -line the cricket; August, 2014. Available from: https://lion.app.box.com/file/415775152695. Accessed February 9, 2022.

82. Kopetz S, Grothey A, Van Cutsem E, et al. Encorafenib plus cetuximab with or without binimetinib for BRAF V600E metastatic colorectal cancer: updated survival results from a randomized, three-arm, phase III study versus choice of either irinotecan or FOLFIRI plus cetuximab (BEACON CRC). J Clin Oncol. 2020;38(15_suppl):4001. doi:10.1200/jco.2020.38.15_suppl.4001

83. Sartore-Bianchi A, Trusolino L, Martino C, et al. Dual-targeted therapy with trastuzumab and lapatinib in treatment-refractory, KRAS codon 12/13 wild-type, HER2-positive metastatic colorectal cancer (HERACLES): a proof-of-concept, multicentre, open-label, phase 2 trial. Lancet Oncol. 2016;17(6):738-746. doi:10.1016/S1470-2045(16)00150-9

84. Meric-Bernstam F, Hurwitz H, Raghav KPS, et al. Pertuzumab plus trastuzumab for HER2-amplified metastatic colorectal cancer (MyPathway): an updated report from a multicentre, open-label, phase 2a, multiple basket study. Lancet Oncol. 2019;20(4):518-530. doi:10.1016/S1470-2045(18) 30904-5

85. Siena S, Di Bartolomeo M, Raghav KPS, et al. A Phase II, multicenter, open-label study of trastuzumab deruxtecan (T-DXd; DS-8201) in patients (pts) with HER2-expressing metastatic colorectal cancer (mCRC): DESTINY-CRC01. J Clin Oncol. 2020;38(15_suppl):4000. doi:10.1200/ jco.2020.38.15_suppl.4000

86. Overman MJ, McDermott R, Leach JL, et al. Nivolumab in patients with metastatic DNA mismatch repair-deficient or microsatellite instability-high colorectal cancer (CheckMate 142): an open-label, multicentre, phase 2 study. Lancet Oncol. 2017;18(9):1182-1191. doi:10.1016/S1470-2045(17)30422-9

87. Le DT, Kim TW, van Cutsem E, et al. Phase II open-label study of pembrolizumab in treatment-refractory, microsatellite instability-high/mismatch repair-deficient metastatic colorectal cancer: KEYNOTE-164. J Clin Oncol. 2020;38(1):11-19. doi:10.1200/JCO.19.02107

88. Le DT, Uram JN, Wang H, et al. PD-1 blockade in tumors with mismatch-repair deficiency. N Engl J Med. 2015;372(26):2509-2520. doi:10.1056/ NEJMoa1500596 
89. Bray F, Ferlay J, Soerjomataram I, Siegel RL, Torre LA, Jemal A. Global cancer statistics 2018: GLOBOCAN estimates of incidence and mortality worldwide for 36 cancers in 185 countries. CA Cancer J Clin. 2018;68(6):394-424. doi:10.3322/caac.21492

90. Sgouros J, Aravantinos G, Dragasis S, et al. Reintroduction of irinotecan and oxaliplatin as a combination (IROX regimen) in heavily pretreated colorectal cancer patients - A single-center experience. Forum Clin Oncol. 2013;4(3):13-18.

\section{Publish your work in this journal}

Cancer Management and Research is an international, peer-reviewed open access journal focusing on cancer research and the optimal use of preventative and integrated treatment interventions to achieve improved outcomes, enhanced survival and quality of life for the cancer patient. The manuscript management system is completely online and includes a very quick and fair peer-review system, which is all easy to use. Visit http://www.dovepress.com/testimonials.php to read real quotes from published authors.

Submit your manuscript here: https://www.dovepress.com/cancer-management-and-research-journal 